\title{
Geología y geocronología de las litologías aflorantes en el tramo Mogotes-San Joaquín (sector SW del Macizo de Santander)
}

\author{
Luis Carlos Mantilla-Figueroa ${ }^{1 *}$; Carlos Alberto García-Ramírez ${ }^{1}$
}

DOI: http://dx.doi.org/10.18273/revbol.v40n1-2018008 @ (1)

Forma de citar: Mantilla-Figueroa, L.C., y García-Ramírez, C.A. (2018). Geología y geocronología de las litologías aflorantes en el tramo Mogotes-San Joaquín (sector SW del Macizo de Santander). Boletín de Geología, 40(1), 123-144. Doi: 10.18273/revbol.v40n1-2018008.

\section{RESUMEN}

En el sector SW del Macizo de Santander (concretamente en el área de los municipios Mogotes y San Joaquín) afloran rocas Paleozoicas (con y sin metamorfismo), las cuales han sido agrupadas y cartografiadas como parte de la Formación Floresta (de edad Devónico). Estudios realizados en el marco del presente trabajo, muestran que ésta formación puede ser dividida en al menos tres miembros: (a) un miembro basal con foliación metamórfica (compuesto principalmente de rocas de aspecto filítico de grano fino a ligeramente conglomeraticas, de composiciones cuarzosas-pelíticas) con edades U-Pb en zircones detríticos de $410 \mathrm{Ma}$ (Devónico Temprano); (b) un miembro medio sin evidencias de metamorfismo (compuesto mayoritariamente de areniscas y lodolitas) con edades U-Pb en zircones detríticos en torno a 372 Ma (límite Devónico Medio-Tardío) y; (c) un miembro superior (predominantemente lodolítico), el cual no pudo ser datado por dificultados para encontrar y concentrar sus zircones detríticos (probablemente de edad Devónico Tardío?). Con base en las máximas edades estratigráficas obtenidas (derivadas de las edades $\mathrm{U}-\mathrm{Pb}$ en zircones detríticos ya mencionadas), se propone correlacionar temporalmente el miembro basal con la Formación Tíbet y el miembro medio con la Formación Floresta. Aunque el miembro superior no ha podido ser datado, se infiere que éste podría correlacionarse temporalmente con la Formación Cuche (unidades descritas en el Macizo de Floresta). Estratigráficamente por encima de las rocas Devónicas antes referidas, se observan capas relativamente restringidas de areniscas calcáreas y abundantes calizas, margas y lodolitas. Con base en estudios paleontológicos previos y edades U-Pb en zircones detríticos aquí obtenidas (en rocas lodolíticas de la parte superior de éste registro sedimentario; pico de edades en torno a $288 \mathrm{Ma}$ ), es posible sugerir que éstas rocas se correlacionan con la unidad denominada 'Paleozoico del Rio Nevado' (consideradas de edad Carbonífero-Pérmico).

Palabras clave: Macizo de Santander; Mogotes; San Joaquín; Formación Floresta; Rocas Paleozoicas.

\section{Geology and geochronology of the outcropping lithologies in the Mogotes-San Joaquín section (SW sector of the Santander Massif)}

\begin{abstract}
In the southwestern of the Santander Massif (specifically in the area of Mogotes and San Joaquín towns) outcrop Paleozoic rocks (with and without metamorphism), which have been grouped and mapped as part of the Floresta Formation (Devonian in age). Studies carried out in the framework of this work show that this formation can be divided at least into three members: (a) a basal member with metamorphic foliation (composed mainly of fine-grained and slightly conglomeratic phyllite-like rocks, quart-pelitic in composition) with detrital zircon U-Pb ages of $410 \mathrm{Ma}$ (Early Devonian); (b) a middle member with no evidence of metamorphism (composed mostly of sandstone and mudstone) with detrital zircon U-Pb ages around 372 Ma (Late-Middle Devonian boundary) and; (c) an upper member (predominantly mudstone), which could not be dated by difficulties to find and concentrate their detrital zircons (probably late Devonian in age?). Based on the maximum stratigraphic ages here obtained (derived from the detrital zircon $\mathrm{U}-\mathrm{Pb}$ ages already mentioned), it is proposed to correlate (in time) the basal member with the Tibet Formation and the middle member with the Floresta Formation. Although the upper member could not be dated, it is inferred that this could be temporarily correlated with the Cuche Formation (units described for the Floresta Massif). Stratigraphically above the Devonian rocks (previously referred), layers of calcareous sandstones (relatively restricted), abundant limestones, calcareous mudstones and mudstones are observed. Based on previous paleontological studies and detrital zircon $\mathrm{U}-\mathrm{Pb}$ ages here reported (in mudstones of the upper part of this sedimentary record, with a peak age around $288 \mathrm{Ma}$ ), it is possible to suggest that these rocks correlate with the unit called 'Paleozoic of the Nevado River' (considered Carboniferous-Permian in age).
\end{abstract}

Keywords: Santander Massif; Mogotes; San Joaquin; Floresta Formation; Paleozoic rocks.

${ }^{1}$ Escuela de Geología, Universidad Industrial de Santander, Bucaramanga, Santander, Colombia. (*)lcmantil@uis.edu.co, cgarciar@uis.edu.co 


\section{INTRODUCCIÓN}

El sector SW del Macizo de Santander (MS), en donde se localiza el área del presente estudio, se proyecta estructuralmente en inmediaciones al segmento sur de las Fallas Lebrija y Bucaramanga (según Velandia et al., 2017), más concretamente en el tramo en donde éstas sufren una ramificación que posteriormente se conectan a las fallas de Soapaga y Boyacá (ver FIGURA 1). Las litologías predominantes en ese sector han sido agrupadas y cartografiadas como parte de la denominada Formación Floresta (metamorfoseada), la cual se considera de edad Devónico (Ward et al., 1973; Vargas et al., 1981). Sin embargo, estudios paleontológicos posteriores sugieren que esas mismas litologías son de edad Carbonífero/ Pérmico y por consiguiente deben ser agrupadas dentro de una unidad litológica que se denominó como Formación Mogotes (Moreno-Sánchez et al., 2005).

Con el propósito de precisar las edades de las litologías aflorantes en el área referida (sus máximas edades estratigráficas o máximas edades de depositación), y de esta manera poder contribuir al esclarecimiento de la problemática mencionada (Formación Floresta vs Formación Mogotes), se realizaron dataciones $\mathrm{U}-\mathrm{Pb}$ en zircones detríticos presentes en aquellas rocas aflorantes en el tramo Mogotes-Cerro Los Cacaos (vía MogotesSan Joaquín; área en donde se suscitó la problemática referida). Previo a este estudio geocronológico mencionado, se realizaron trabajos de campo, para fines de poder establecer mejor las relaciones entre las diferentes unidades de rocas observadas.

En el contexto anteriormente referido, se espera que los datos aportados en éste trabajo puedan contribuir al conocimiento sobre la evolución geológica de este sector del Macizo de Santander.

\section{ANTECEDENTES Y CONTEXTO GEOLÓGICO}

El registro sedimentario más antiguo aflorante en el Macizo de Santander (MS), temporalmente se asocia con la Formación Floresta, la cual es considerada de edad Paleozoico Tardío (Devónico Medio, es decir, entorno a 390-380 Ma), según estudios paleontológicos realizados por Boinet et al. (1985). Por otro lado, las rocas con metamorfismo regional más jóvenes del MS, temporalmente se han asociado con la unidad Ortogneis, considerada de edad Paleozoico Temprano (Ordovícico Temprano, es decir, en torno a $480-470$ Ma), según datos de Restrepo-Pace y Cediel (2010). No obstante, estudios relativamente recientes desarrollados en diferentes sectores del MS (Mantilla-Figueroa et al., 2016a; 2016b), han mostrado que el intervalo temporal comprendido entre las rocas más jóvenes afectadas por metamorfismo regional y el registro sedimentario más antiguo presente en el MS, puede ser más complejo que lo anteriormente señalado. En este sentido apuntan los datos geocronológicos reportados por Van der Lelij et al. (2015), quienes reportan la presencia de rocas afectadas por metamorfismo regional (tipo Ortogneis) en el sector del Páramo de Berlín (sector central del MS), con edades del Ordovícico Tardío. Asimismo, los datos reportados por Mantilla-Figueroa et al. (2015), muestran que en el área del Cañón del Chicamocha (sector SW del MS) también afloran rocas metamórficas (metamorfismo regional) de edad Ordovícico Tardío ( $\sim 50 \mathrm{Ma}$; correspondiente a unidad que de manera preliminar sugirieron llamar como Filitas de San Pedro). En este contexto de ideas, se infiere que las rocas más jóvenes en el MS afectadas por metamorfismo regional (no metamorfismo de contacto, ni dinamo-térmico), posiblemente serían del Ordovícico Tardío. Sin embargo, en un estudio aún más reciente (Cardona et al., 2016), se propone que el MS ha sido afectado por eventos de metamorfismo regional aún mucho más jóvenes, hasta el punto de asociar un protolito de edad Carbonífero Tardío ( $311 \mathrm{Ma}$, según edades $\mathrm{U}-\mathrm{Pb}$ en circones detríticos) con la Formación Silgará (rocas aflorantes en el área de Mutiscua; sector central de MS) y considerar que éste protolito sufrió deformación y metamorfismo regional a finales del Carbonífero y comienzos del Pérmico $(\sim 300 \mathrm{Ma})$.

La anomalía termal derivada del magmatismo de finales del Triásico Tardío y el comienzo del Jurásico Temprano $\left(\mathrm{T}_{3}-\mathrm{J}_{1} ; \sim 210-200 \mathrm{Ma}\right)$, ha sido igualmente considerada como responsable del desarrollo de una mineralogía metamórfica en el MS. Cardona et al. (2016), señala que este evento magmático generó un metamorfismo que se sobre-impuso a los eventos metamórficos del Paleozoico Tardío (C-P) ya mencionados. Zuluaga et al. (2017), relacionan igualmente el desarrollo del arco magmático de edad $\mathrm{T}_{3}-\mathrm{J}_{1}$ con un metamorfismo de baja presión, el cual favoreció tanto la formación de cordierita, como de asociaciones minerales metamórficas propias de un ambiente de extensión cortical, el cual afectó prácticamente a todo el Macizo de Santander.

\section{METODOLOGÍA}

En el marco del presente estudio se realizaron trabajos de campo para fines de reconocimiento y muestreo de las litologías objeto de la presente investigación. El análisis macroscópico de las muestras se realizó en el laboratorio de microscopía óptica de la Escuela de Geología de la Universidad Industrial de Santander (UIS). 


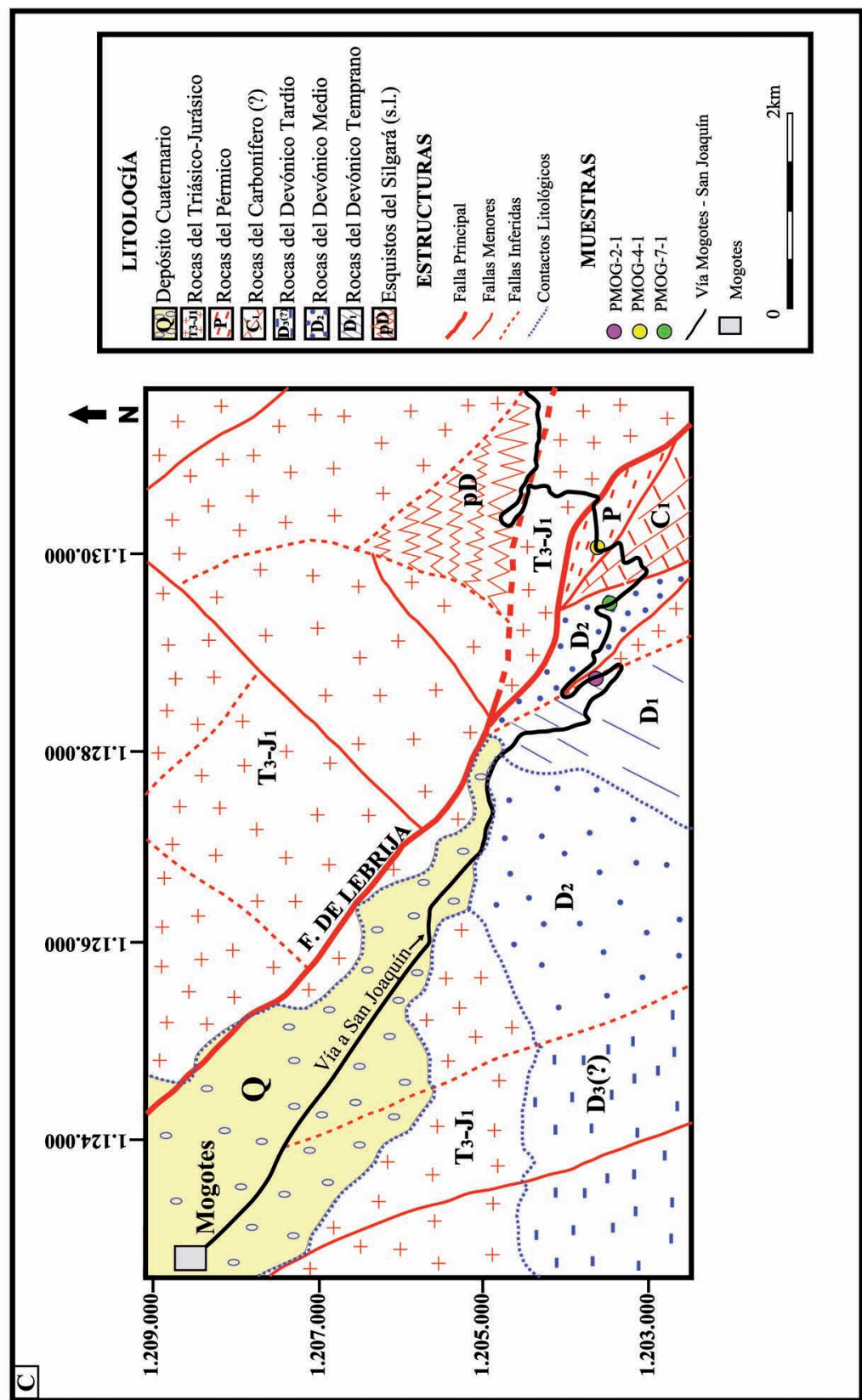

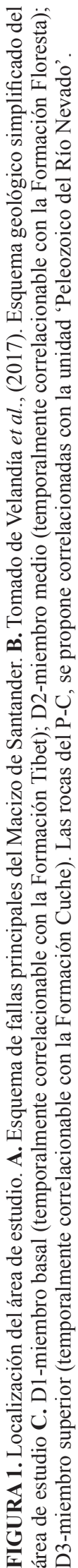
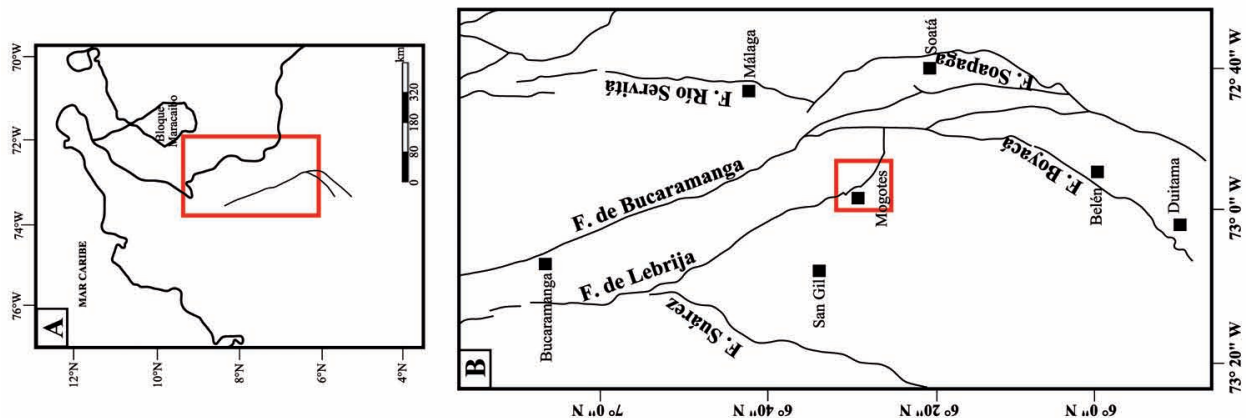
La extracción de zircones de las muestras colectadas para análisis de geocronología U-Pb, se realizó utilizando los métodos tradicionales en ZirChron LLC (Tucson, AZ), mientras que las dataciones $\mathrm{U}-\mathrm{Pb}$ en zircones detríticos fueron realizadas mediante la técnica LA-ICP-MS en el laboratorio de geoquímica isotópica de la Universidad Estatal de Washington (WSU, USA). Los procedimientos analíticos seguidos durante estos análisis se documentan en Chang et al. (2006); y también se resumen en el apartado 'Metodología', en Mantilla-Figueroa et al. (2013).

\section{RESULTADOS}

\section{Unidades litológicas}

En el área objeto de estudio se reconocieron durante los trabajos de campo, litologías metamórficas, ígneas y sedimentarias de edad Fanerozoico. Estas litologías fueron (de la más antigua a las más joven) agrupadas en las siguientes unidades y formaciones: (1) Unidad Esquistos del Silgará (s.l.) de edad pre-Devónico; (2) Formación Floresta de edad Devónico; (3) Rocas sedimentarias predominantemente calcáreas de edad Carbonífero (Temprano?); (4) Rocas sedimentarias predominantemente lodolíticas de edad Pérmico; (5) Rocas ígneas plutónicas y subvolcánicas félsicas de edad Triásico Tardío-Jurásico Temprano; (6) diques básicos de edad Jurásica? y; (7) depósitos sedimentarios representados principalmente por el abanico de Mogotes (de edad Cuaternaria).

(1) Las rocas de edad pre-Devónica aflorantes en el área objeto de estudio son principalmente de tipo filitas, de composiciones pelíticas, semipelíticas y meta-areniscas cuarzosas (ocasionalmente con bandas milimétricas de cuarzo-sericita; FIGURAS $2 \mathrm{G}$ y $2 \mathrm{H}$ ). La ausencia de fósiles Paleozoicos en estas rocas y el mejor desarrollo de sus planos de foliación metamórfica, entre otros criterios, fueron utilizados como rasgos distintivos para diferenciar estas litologías de aquellas pertenecientes a la denominada Formación Floresta metamorfoseada. Aunque la presencia de esquistos también se reconoce en el área, éstos no se describen aquí, debido a que están por fuera del recuadro del área estudiada señalado en la FIGURA 1.

(2) Las rocas de la Formación Floresta en el área de estudio han sido referidas en estudios previos como rocas metamorfoseadas (Ward et al., 1973; Vargas et al., 1981). Esta unidad reportada por primera vez en cercanías a la localidad homónima en el departamento de Boyacá (Caster, 1939), es considerada desde los trabajos de Botero (1950) como de edad Devónica (concretamente Devónico Medio) y ha sido observada suprayaciendo a las rocas metamórficas de edad pre-Devónico e infrayaciendo a su vez a las rocas sedimentarias de la Formación Cuche (compuesta principalmente de pizarras arcillosas y argilitas), considerada de edad Devónico Tardío (según Cardona et al., 2016).

Durante el desarrollo del presente estudio se reconocieron por primera vez tres diferentes miembros composicionales, a diferencia de estudios anteriores, en donde solo se hacía referencia indistintamente a una única formación denominada Formación Floresta (Vargas et al., 1981). Estos tres miembros mencionados (FIGURAS 2A a 2F) fueron identificados y diferenciados con base en su composición y presencia o ausencia de planos de anisotropía (derivados de antiguos eventos tectono-termales). Estos tres miembros se denominan en este estudio como: (a) miembro basal (composicionalmente más arenoso-conglomerático; FIGURAS 2E y 2F), (b) miembro medio (más arenoso-lodoso; FIGURAS 2A a 2D) y; (c) miembro superior (predominantemente lodoso).

El miembro basal de la Formación Floresta (FIGURA 1) se caracteriza por presentar un aspecto muy similar a las filitas del pre-Devónico. Posiblemente su diferencia principal radica en que sus componentes siliciclásticos suelen ser predominantemente más arenoso-conglomeráticos (las filitas del pre-Devónico, como diferencia presentan localmente abundante porfidoblastos de magnetita, con tamaños que raramente sobrepasan los 0,3-0,5 cm). Adicionalmente, estas rocas del miembro basal, al ser alteradas por procesos supérgenos, adquieren una tonalidad de color ladrillo-anaranjado muy característico (FIGURA 2F). La evidente re-orientación preferente de los componentes en estas litologías se considera relacionada más con procesos dinamo-térmicos (protomilonitas?), más que con procesos propios de un metamorfismo regional.

El miembro medio de la Formación Floresta, a diferencia del miembro basal, se caracteriza por presentar un aspecto claramente sedimentario, en donde predominan capas de areniscas y lodolitas de espesores variables. Posiblemente una característica distintiva de este miembro es la presencia de intercalaciones de capas con espesores $<10 \mathrm{~cm}$, compuestas de areniscas de tamaño de grano medio a muy fino, predominantemente cuarzosas, $y$ 
capas de lodolitas de tamaño limo y de color negro oscuro, debido al contenido de materia orgánica (FIGURA 2D). Estas rocas localmente presentan venas de cuarzo-clorita, las cuales desarrollan texturas de relleno tanto masiva como fibrosa (FIGURA 2B). Estas venas de relleno hidrotermal cuando son afectadas por procesos de alteración supérgenos, suelen lixiviar la clorita, dejando en su lugar oquedades de formas tubulares y una pigmentación hematítica en los cuarzos fibrosos aledaños (FIGURA 2B).
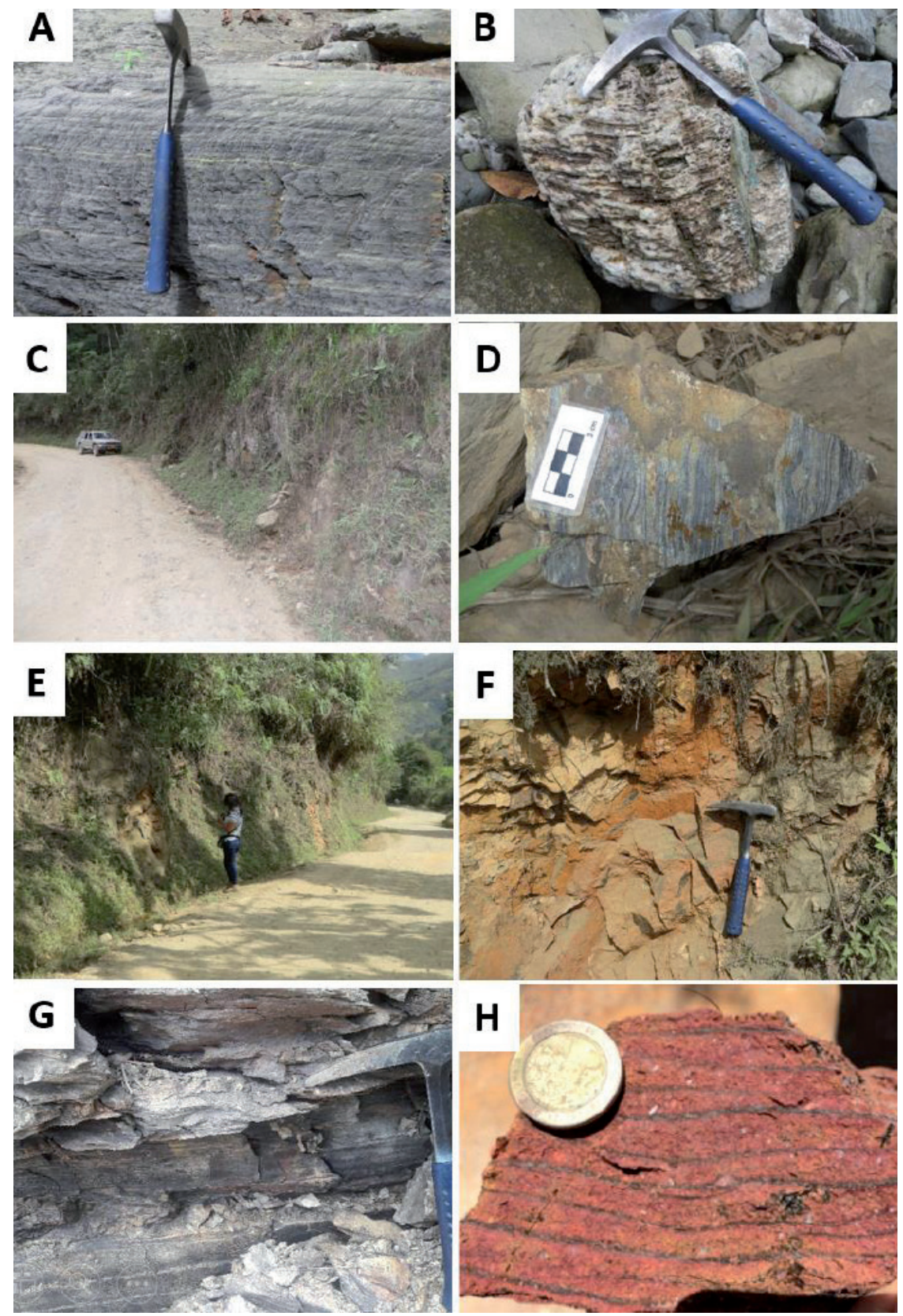

FIGURA 2. Aspecto general de algunas litologías Paleozoicas aflorantes en área de los municipios de Mogotes y San Joaquín (Sector SW del Macizo de Santander). Rocas sedimentarias compuestas por intercalación de areniscas y lodolitas orgánicas, localmente con desarrollo de Pizarrosidad (A, C y D) y puntualmente con presencia de venas de cuarzo y clorita con textura de relleno fibroso (B). Infrayaciendo estas litologías, afloran rocas de aspecto filítico, compuestas de psamitas-semipelítas ( \pm pelíticas; E, F). Las rocas de bajo grado de metamorfismo del pre-Devónico, están representadas en filitas (G), con presencia ocasional de micro-porfidoblastos de magnetita, localmente con bandas paralelas de cuarzo-sericita (alteración hidrotermal) de espesores entorno a 0,5 $\mathrm{cm}(\mathbf{H})$. Estas últimas, resaltan en aquellas rocas con pigmentación hematítica, formada a consecuencia de procesos de alteración supérgena. 
El miembro superior de la Formación Floresta se caracteriza por la presencia predominante de rocas de grano muy fino, aquí referidas grupalmente como lodolitas de colores grises a negras, con evidente desarrollo de planos de clivaje de carga y muy localmente clivajes tipo pencil.

(3) Las rocas sedimentarias predominantemente calcáreas de edad Carbonífero (Inferior?), se caracterizan por la presencia, en la parte más basal observada en este registro sedimentario, de cuarzoareniscas de colores claros y grano medio, las cuales al ser meteorizadas dan una apariencia de un material arenoso de aspecto sucio de tonalidades marrones oscuras (FIGURAS $3 \mathrm{G}$ y $3 \mathrm{H}$ ). Con estas rocas también se relaciona la presencia de calizas grises, margas y lodolitas calcáreas mayoritariamente (FIGURAS 3E, 3F, 3D). Localmente se han observado algunos bloques rodados de tamaños métricos, compuestos de una caliza recristalizada con presencia de sulfuros diseminados (pirita, calcopirita). Estos bloques calcáreos observados con importante recristalización, también presentan una gran cantidad de venas hidrotermales esencialmente de cuarzo, con espesores promedio de 5-10 cms (FIGURA 3C). Considerando que los materiales calcáreos más recristalizados en éste sector presentan una gran profusión de venas hidrotermales y sulfuros diseminados (no todas las rocas calcáreas y lodolitas calcáreas alcanzan el mismo grado de recristalización), se presume que esta secuencia pudo haber sido localmente afectada por procesos hidrotermales (metamorfismo hidrotermal). Estas rocas se relacionan en edad con un registro del Carbonífero Inferior, tomando en consideración los datos reportados en Moreno-Sánchez et al. (2005) y apoyados en la comunicación verbal del paleontólogo alemán Didier Trapp.

(4) Las rocas sedimentarias predominantemente lodolíticas del Pérmico, se diferencian de las rocas sedimentarias del Carbonífero Inferior (?) y de la Formación Floresta, por ser rocas que no desarrollan ninguna reorientación preferente, ni recristalización evidente a escala macroscópica. Estas rocas lodolíticas están muy restringidas en el área (ver FIGURA 3A y 3B), y su edad Pérmica ha sido determinada con base en las edades U-Pb de sus zircones detríticos (ver apartado Geocronología). Estas litologías son cortadas por rocas ígneas principalmente rioliticas de edad Triásico TardíoJurásico Temprano.
(5) Las rocas ígneas plutónicas y subvolcánicas félsicas de edad Triásico Tardio-Jurásico Temprano, son las que presentan una mayor extensión en el área de estudio (ver FIGURAS 1 y 4). Las litologías plutónicas observadas son mayoritariamente de composición cuarzomonzonitica y monzogranitica. Estas rocas presentan textura fanerítica y muy localmente suelen ser porfirítico-faneríticas (FIGURAS 4F, 4G y 4H). Estas litologías suelen ser cortadas por diques de leucogranitos y por diques de riolitas con textura afanítica-porfirítica. Estas últimas, son más abundantes en proximidad al municipio de San Joaquín. Las edades absolutas de estas litologías (pertenecientes ampliamente al denominado Batolito de Mogotes, según Ward et al., 1983), se presentan y se describen con un gran detalle en Correa et al. (2016). Adicionalmente, aunque comparativamente de manera muy restringida, se presentan algunos diques graníticos de textura pegmatitica, como los observados en el sector de la vereda Las Flores (al norte del Municipio de Mogotes). Estas rocas ígneas félsicas plutónicas y subvolcánicas, localmente desarrollan franjas o bandas de un color verde manzana, de espesores que pueden alcanzar los 2-3 metros, compuestas principalmente de cuarzo-sericita (FIGURAS 4E y 4H). Estas bandas se consideran el resultado de alteraciones hidrotermales hipógenas, formadas con posterioridad al magmatismo del $\mathrm{T}_{3}-\mathrm{J}_{1}$ ya referido. Finalmente, vale la pena igualmente mencionar que de manera puntual también se reconoce la presencia de cordierita, confinada a zonas de contacto entre las litologías del Paleozoico Tardío mencionadas y los cuerpos ígneos aquí relacionados.

(6) Diques básicos de edad Jurásico (?), clasificados como de tipo micro-gabros (también llamados doleritas o diabasas), se observan más claramente en aquellos sectores en donde éstos cortan las rocas ígneas félsicas referidas en las anteriores líneas (FIGURAS 4C y 4D). Estos diques suelen variar en espesor entre 0,3 y 3,0 $\mathrm{m}$ de espesor en promedio, $\mathrm{y}$ generalmente se encuentran completamente meteorizados (salvo algunas excepciones), hasta el punto de perder completamente toda su textura y mineralogía ígnea, dejando solo un material arcilloso de colores ladrillo a ocre. No se ha podido establecer la relación temporal entre las bandas con alteración hidrotermal de tipo cuarzosericita y los diques de diabasa, pero se presume una relación temporal muy cercana entre estos. 
(7) Los depósitos sedimentarios representados principalmente en el Abanico de Mogotes (de edad Cuaternaria), forman el extenso valle sobre el cual reposa el municipio de Mogotes. El ápice de este depósito en forma de abanico apunta en dirección ESE (hacia la línea divisoria que separa Mogotes y San Joaquín), desde donde progresivamente se ensancha en dirección hacia el WNW. Un aspecto muy curioso en la disposición de este abanico es su proximidad a la falla de dirección aproximada WNW-ESE, la cual ha sido considerada por Velandia et al. (2017), como la proyección más sur de la Falla de Lebrija. No se descarta que ésta falla haya podido controlar el desarrollo y la actual localización del Abanico de Mogotes (ver FIGURAS 1, 4A, 4B).
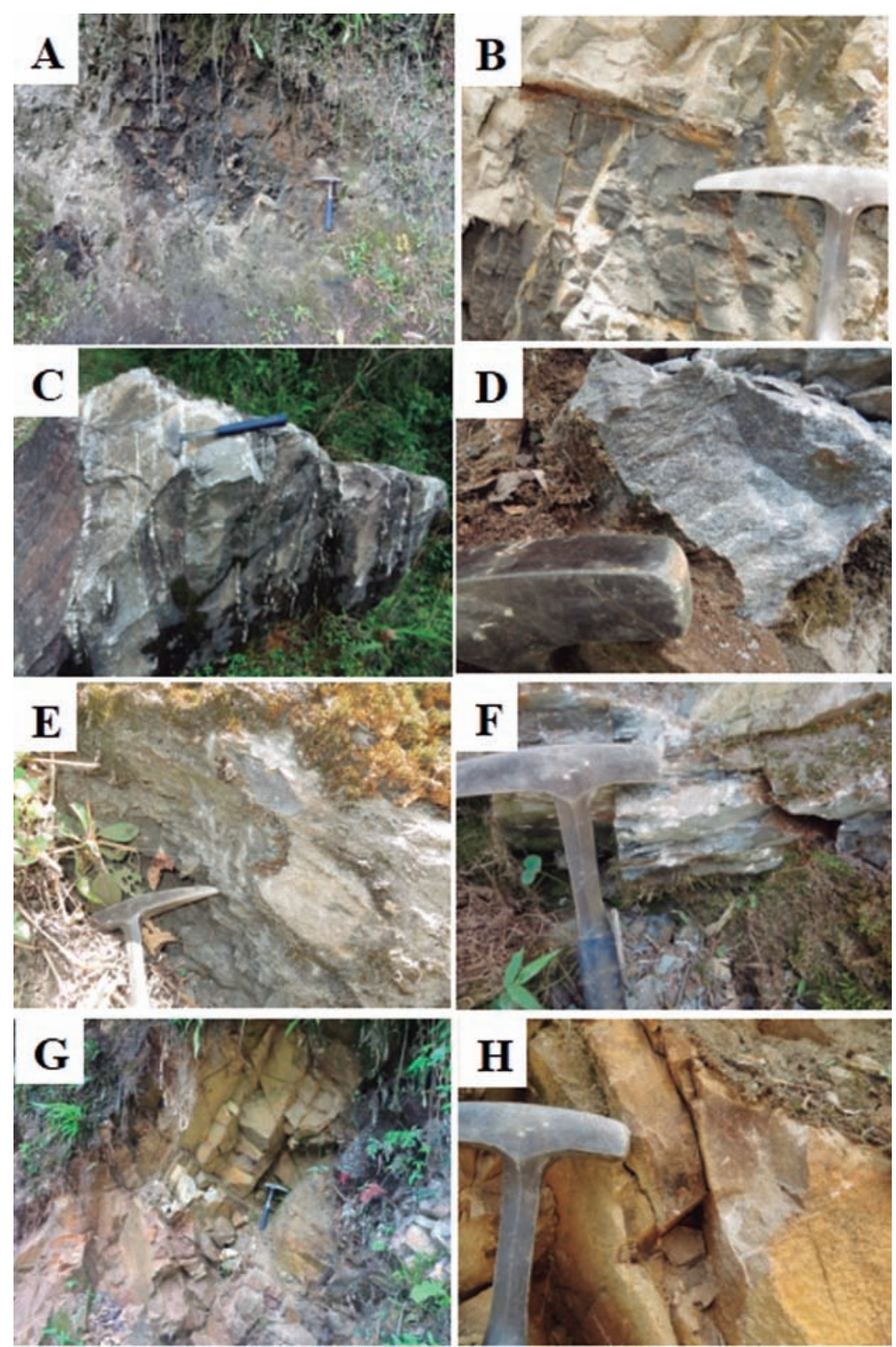

FIGURA 3. Aspecto general de algunas litologías (de edades comprendidas entre el Carbonífero-Pérmico-Triásico), aflorantes por la vía Mogotes-Cerro Los Cacaos (Sector SW del Macizo de Santander). A, B: Rocas sedimentarias Pérmicas tipo lodolita orgánica (con presencia ocasional de oquedades derivadas posiblemente de la lixiviación de antiguos fósiles de tamaño milimétrico). D, E, F: infrayaciendo las anteriores litologías, afloran rocas calcáreas (margas y presencia de fósiles) del Carbonífero Inferior?, las cuales localmente presentan recristalización, puntuales sulfuros y venas de cuarzo (C). G, H: Infrayaciendo estas litologías, afloran algunas capas de cuarzo-areniscas, las cuales, al alterarse, a visu, dan un aspecto marrón sucio (¿debido a antiguos cementos ricos en $\mathrm{Fe}$ ?). 

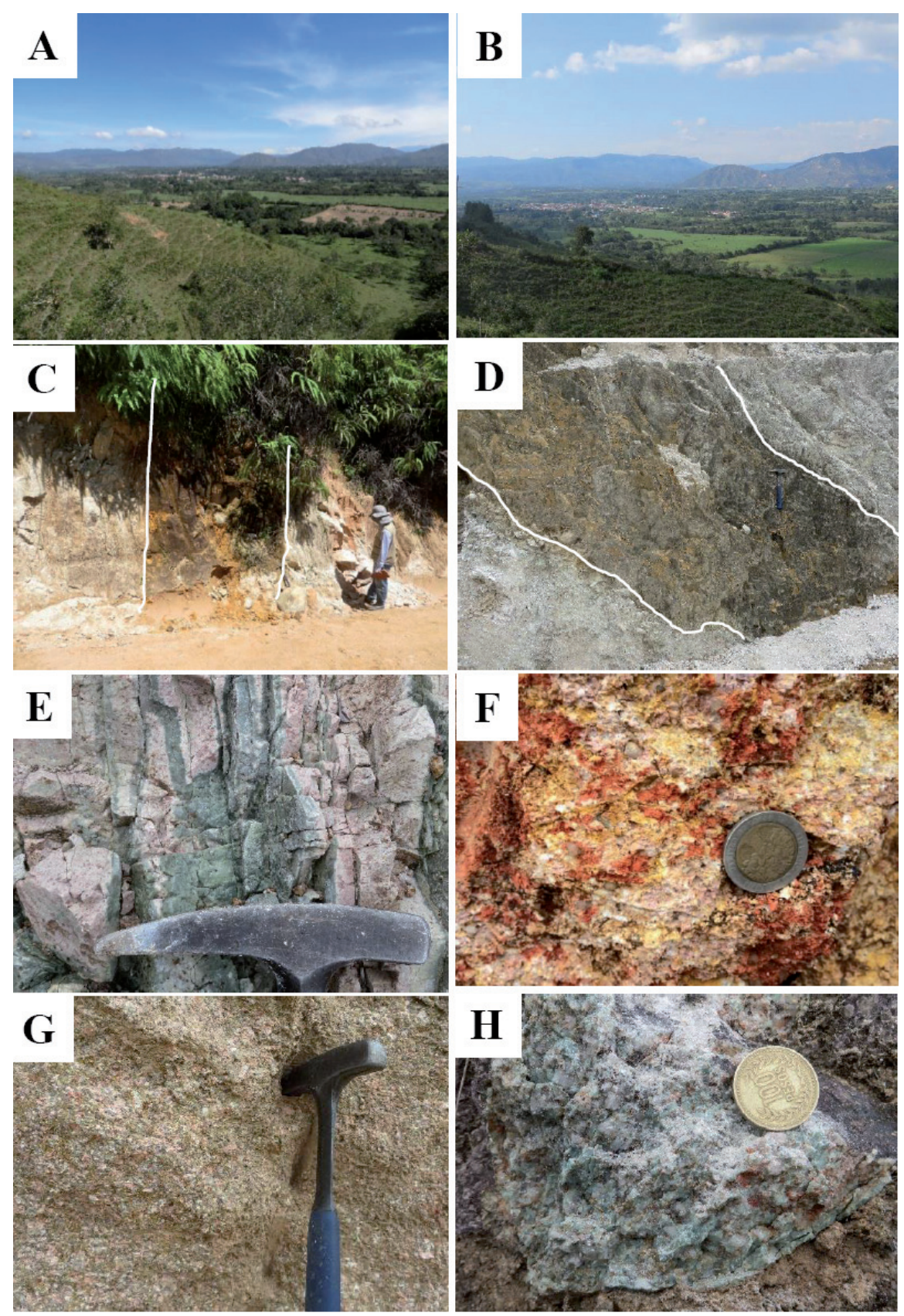

FIGURA 4. Aspecto general de las litologías ígneas máficas (diques de diabasas con diferente grado de meteorización; C y D), considerados de edad Jurásica (?) y; rocas félsicas (diques riolíticos porfiríticos afectados por alteración hidrotermal fílica-Ey alteración argílica supérgena-F-G; rocas plutónicas graníticas-G-, localmente también afectadas por alteración hidrotermal hipogena-H), consideradas de edad Triásico Tardío-Jurásico Temprano. Las FIGURAS A y B muestran el aspecto general del área ocupada por el abanico de Mogotes, considerado de edad Cuaternaria.

\section{Aspectos generales de las rocas colectadas para análisis geocronológicos}

Tres muestras fueron colectadas para ser analizadas mediante geocronología U-Pb en zircones detríticos. Estas muestras son la PMOG-2-1, PMOG-7-1, PMOG4-1 (ver localización y coordenadas en FIGURA 1 y TABLA 1).
La muestra PMOG-2-1 (FIGURA 2F), clasificada como una filita cuarzosa, se caracteriza por presentar un color ocre a gris, aunque puede adquirir tonalidades anaranjadas cuando son afectadas por procesos de meteorización (alteración supérgena). Estas rocas suelen tener un tamaño de grano fino a muy fino y sus componentes presentan una leve orientación preferente. La muestra 
colectada, desde el punto de vista mineralógico, consta de cuarzo, moscovita, clorita, plagioclasa, rutilo y opacos. El cuarzo (40\%) consiste en cristales xenoblásticos a subidioblásticos heteroblásticos, con bordes irregulares y tamaño de grano fino a muy fino. Son comunes las inclusiones de muscovita. La muscovita (20\%) se presenta como individuos laminares alargados, heteroblásticos, orientados, definiendo la estructura de la roca. La clorita (10\%) se presenta a manera de individuos alargados, asociados a la moscovita en contacto neto. Otro tipo de clorita (10\%) aparece rellenando fracturas como agregados fibroso-radiales. La plagioclasa (5\%) son cristales xenoblásticos a subidioblásticos, algunos cristales están maclados y están asociadas en contacto neto a moscovita y clorita. Los opacos (5\%) aparecen como porfidoblastos idioblasticos de forma cubica a rectangular. Es frecuente la presencia de óxidos (10\%) rellenando fracturas. La textura predominante de la roca es lepidogranoblástica, aunque se observa textura porfidoblástica en matriz granolepidoblástica.

La muestra PMOG-7-1 es una roca de aspecto claramente sedimentario (FIGURA 2D), en la cual se observan intercalaciones de capas de areniscas y lodolitas, principalmente. Los espesores de estas capas suelen variar de fino a muy fino $(<10 \mathrm{~cm} \mathrm{y}>1 \mathrm{~cm})$, aunque ocasionalmente se observan intercalaciones de estas mismas litologías, pero de espesores menores a $1 \mathrm{~cm}$ (láminas sedimentarias). Las capas o láminas de arenisca referida suelen ser de grano muy fino y se componen mayoritariamente de cuarzo y en menor proporción de muscovita detrítica. Las capas y láminas de lodolitas, suelen ser de color negro, debido al contenido de materia orgánica. Estas lodolitas igualmente suelen presentar muscovita detrítica. Estos materiales sedimentarios referidos, suelen presentar localmente un desarrollo de planos de anisotropía muy penetrativos $\left(\mathrm{S}_{2}\right)$, generalmente dispuestos perpendicularmente a los planos de estratificación y planos de carga litostática (So $\sim \mathrm{S}_{1}$ cortados por planos $\mathrm{S}_{2}$; ver FIGURA 2A). Los planos $\mathrm{S}_{2}$ (planos de pizarrosidad) medidos en la vía Mogotes-Cerro Los Cacaos, presentan una disposición espacial $210^{\circ} / 80$, mientras que los planos So $\sim \mathrm{S}_{1}$ presentan valores aproximados de $140^{\circ} / 25^{\circ}$.

La muestra PMOG-4-1, clasificada como una lodolita arenosa, se caracteriza por presentar un color gris oscuro a casi negro, evidenciado por presencia de materia orgánica grafitosa muy fina. Se observan sectores lixiviados completamente y fragmentos de roca más pelítica. Presenta tamaño de grano muy fino a ultrafino. La estructura es ligeramente orientada y algunas veces con fracturas rellenas de minerales arcillosos, óxidos o clorita. Son comunes las venas de cuarzo y clorita concordantes con la orientación de la estructura. Esta roca en superficie presente oquedades milimétricas, las cuales se interpretan como moldes derivados de la lixiviación de antiguos fósiles (ver FIGURA 3A y 3B).

\section{Geocronología U-Pb en zircones detríticos}

Con el objetivo de poder establecer la máxima edad estratigráfica mediante dataciones U-Pb en zircones detríticos, de aquellas unidades de roca aflorantes en el tramo comprendido entre el municipio de Mogotes y el denominado Cerro Los Cacaos (vía hacia el municipio de San Joaquín), se colectaron las tres muestras de rocas (PMOG-4-1, PMOG-7-1 y PMOG-2-1) antes relacionadas (TABLA 1; FIGURAS 1, 5 y 6). A continuación, se describen los resultados obtenidos del estudio geocronológico ya referido (de las muestras más antiguas a las más jóvenes).

TABLA 1. Coordenadas y localización geográfica de las litologías colectadas para análisis mediante geocronología U-Pb en zircones detríticos.

\begin{tabular}{|c|c|c|c|c|c|c|c|}
\hline \multirow{2}{*}{ Muestra } & \multicolumn{2}{|c|}{ Coordenadas* } & \multicolumn{3}{|c|}{ Coordenadas locales $* *$} & \multirow{2}{*}{ Localización Geográfica } & \multirow{2}{*}{ Tipo de roca } \\
\hline & Latitud & Longitud & $\mathbf{X}$ & $\mathbf{Y}$ & $\mathrm{Z}$ (msnm) & & \\
\hline PMOG-4-1 & $6^{\circ} 26^{\prime} 10,2 ”$ & $72^{\circ} 54^{\prime} 02,6^{\prime \prime}$ & 1.203 .625 & 1.130 .185 & $\sim 2.254$ & $\begin{array}{c}\text { Vía Mogotes-Cerro } \\
\text { Los Cacaos-San Joaquín }\end{array}$ & Lodolita arenosa \\
\hline PMOG-7-1 & $6^{\circ} 26^{\prime} 05,0^{\prime \prime}$ & $72^{\circ} 54^{\prime} 20,4^{\prime \prime}$ & 1.203 .463 & 1.129.637 & $\sim 2.205$ & $\begin{array}{c}\text { Vía Mogotes-Cerro } \\
\text { Los Cacaos-San Joaquín }\end{array}$ & Pizarra \\
\hline PMOG-2-1 & $6^{\circ} 26^{\prime} 06,6^{\prime \prime}$ & $72^{\circ} 54^{\prime} 43,8^{\prime \prime}$ & 1.203 .512 & 1.128.919 & $\sim 2.129$ & $\begin{array}{c}\text { Vía Mogotes-Cerro } \\
\text { Los Cacaos-San Joaquín }\end{array}$ & Filita cuarzosa \\
\hline
\end{tabular}

* Coordenadas Datum WGS84 (EPSG 4326)

** Coordenadas Planas con Datum Bogotá (Bogota 1975/Colombia Bogota zone (21897)

La muestra PMOG-2-1, tal como se mencionó en anteriores líneas, es una roca de aspecto filitico (debido a la presencia de superficies de aspecto sedoso), con planos de foliación con una disposición espacial de
40/38. Ciento veinte (120) análisis fueron realizados en zircones detríticos presentes en ésta muestra, arrojando edades entre 401,5 $\pm 6,6$ Ma y 2929,3 $\pm 16,5$ Ma (ver TABLA 2; FIGURA 5). Picos prominentes con edades 
en torno a 1045, 770, 545, 455 y $410 \mathrm{Ma}$, entre otros picos menos pronunciados, se evidencian claramente entre las poblaciones de edades que arroja esta muestra (FIGURA 6). Considerando las edades U-Pb en zircones detríticos aquí obtenidas, es posible concluir que la máxima edad estratigráfica (máxima edad de sedimentación del protolito), es Pragiense (Devónico Temprano), tomando como referencia el pico prominente con edades más recientes (410 Ma). No obstante, la presencia de seis (6) zircones con edades menores entre $405,6 \pm 7,1$ y $401,5 \pm 6,6$ (ver TABLA 2) permiten sugerir que esta unidad de roca puede tener una máxima edad de depositación Emsiense (Devónico Temprano).
La presencia de circones detríticos con picos de edades del Meso- y Neo-proterozoico (1045, 770 y $545 \mathrm{Ma}$ ), se interpretan como procedentes principalmente de rocas fuentes más antiguas, como puede ser el caso de las unidades Gneis de Bucaramanga y Esquistos del Silgará (Cordani et al., 2005; Mantilla-Figueroa et al., 2016b, entre otros). Por otro lado, los picos de edades 455 y 410 , se consideran relacionados con los diferentes eventos magmáticos del Paleozoico, documentados ampliamente mediante zircones detríticos en Cardona et al. (2016), entre otros trabajos.
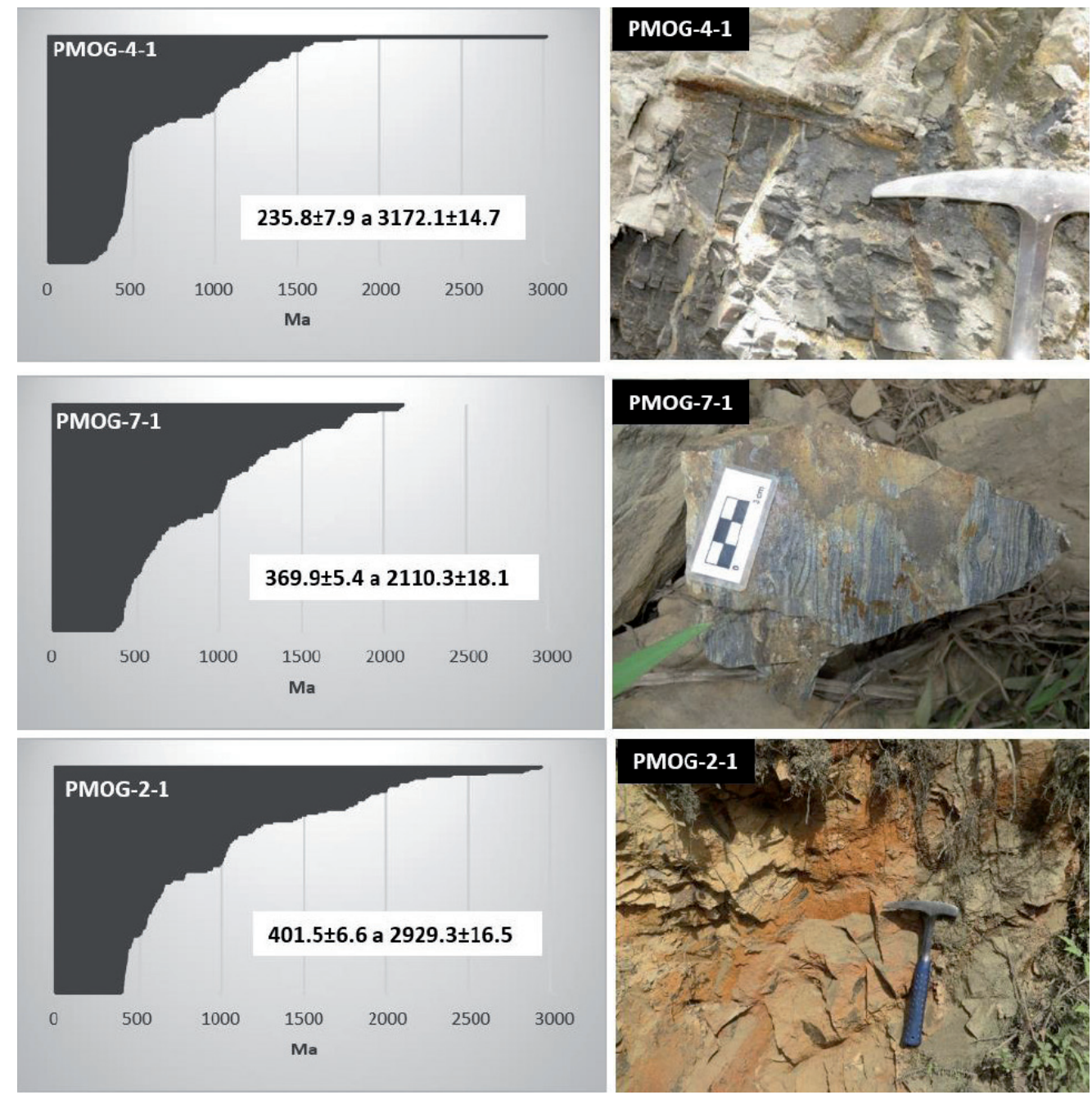

FIGURA 5. Distribución de las edades obtenidas a partir de análisis U-Pb en circones detríticos presentes en las muestras analizadas. PMOG-4-1: Lodolitas orgánicas (sin pizarrosidad, sin aspecto filítico), con una máxima edad estratigráfica del Triásico Medio (Ladiniense). PMOG-7-1: Litologías representadas por intercalaciones de niveles arenosos finos-medios y niveles de lodolitas orgánicas (afectadas por pizarrosidad), con una máxima edad estratigráfica del Devónico Tardío (Fameniense). PMOG-2-1: Litologías psefitas y psamíticas con desarrollo de superficies filiticas (rocas de aspecto filítico), con una máxima edad estratigráfica del Devónico Temprano (Emsiense). 
TABLA 2. Resultados analíticos U-Pb en las diferentes zonas al interior de los circones estudiados en la muestra PMOG-2-1 y sus correspondientes edades (Análisis realizados mediante la técnica LAICP-MS).

\begin{tabular}{|c|c|c|c|c|c|c|c|c|c|c|c|c|}
\hline $\begin{array}{c}\text { Puntos de } \\
\text { análisis } \\
\end{array}$ & $\begin{array}{c}\mathrm{U} \\
\mathbf{p p m} \\
\end{array}$ & $\begin{array}{c}\text { Th } \\
\text { U } \\
\end{array}$ & $\begin{array}{l}238 \mathrm{U} / \\
206 \mathrm{~Pb}\end{array}$ & $\begin{array}{c}1 \text { sigma } \\
\text { (\% error) }\end{array}$ & $\begin{array}{l}207 \mathrm{~Pb} / \\
206 \mathrm{~Pb}\end{array}$ & $\begin{array}{c}1 \text { sigma } \\
\text { (\% error) }\end{array}$ & $\begin{array}{c}\mathrm{Pb206} / 238 \mathrm{U} \\
\text { (age) }\end{array}$ & $\begin{array}{l}1 \text { sigma } \\
\text { (abs err) }\end{array}$ & $\begin{array}{c}207 \mathrm{~Pb} / 206 \mathrm{~Pb} \\
\text { (age) }\end{array}$ & $\begin{array}{l}1 \text { sigma } \\
\text { (abs err) }\end{array}$ & $\begin{array}{c}\text { Best age } \\
\text { Ma }\end{array}$ & $\begin{array}{c}1 \text { sigma } \\
\text { abs err Ma } \\
\end{array}$ \\
\hline PMOG-2-1_1 & 835 & 0,20 & 5,8748 & $1,45 \%$ & 0,0727 & $1,07 \%$ & 1013,3 & 13,6 & 1005,6 & 21,6 & 1005,6 & 21,6 \\
\hline PMOG-2-1_2 & 189 & 1,17 & 2,9200 & $1,62 \%$ & 0,1160 & $1,11 \%$ & 1898,5 & 26,6 & 1895,6 & 19,8 & 1895,6 & 19,8 \\
\hline PMOG-2-1_3 & 1.194 & 0,68 & 7,8253 & $1,53 \%$ & 0,0657 & $1,04 \%$ & 775,3 & 11,2 & 795,8 & 21,7 & 775,3 & 11,2 \\
\hline PMOG-2-1_4 & 4.160 & 0,05 & 10,1428 & $1,51 \%$ & 0,0604 & $0,99 \%$ & 606,2 & 8,7 & 619,4 & 21,1 & 606,2 & 8,7 \\
\hline PMOG-2-1_5 & 324 & 1,46 & 8,8483 & $1,57 \%$ & 0,0697 & $1,87 \%$ & 690,2 & 10,3 & 919,6 & 37,9 & 690,2 & 10,3 \\
\hline PMOG-2-1_6 & 147 & 2,39 & 6,6903 & $1,74 \%$ & 0,0703 & $1,36 \%$ & 898,0 & 14,6 & 937,5 & 27,6 & 937,5 & 27,6 \\
\hline PMOG-2-1_7 & 1.072 & 0,26 & 13,5512 & $1,61 \%$ & 0,0561 & $1,12 \%$ & 459,0 & 7,1 & 455,8 & 24,8 & 459,0 & 7,1 \\
\hline PMOG-2-1_8 & 135 & 0,47 & 5,9870 & $1,69 \%$ & 0,0742 & $1,46 \%$ & 995,7 & 15,5 & 1047,5 & 29,2 & 1047,5 & 29,2 \\
\hline PMOG-2-1_9 & 104 & 0,56 & 2,7443 & $1,70 \%$ & 0,1229 & $1,08 \%$ & 2002,9 & 29,3 & 1999,2 & 19,0 & 1999,2 & 19,0 \\
\hline PMOG-2-1_10 & 498 & 0,39 & 14,6651 & $1,52 \%$ & 0,0554 & $1,30 \%$ & 425,2 & 6,2 & 429,2 & 28,8 & 425,2 & 6,2 \\
\hline PMOG-2-1_11 & 1.540 & 0,04 & 13,5399 & $1,57 \%$ & 0,0560 & $1,14 \%$ & 459,3 & 7,0 & 452,1 & 25,2 & 459,3 & 7,0 \\
\hline PMOG-2-1_12 & 337 & 1,62 & 11,3729 & $1,60 \%$ & 0,0633 & $1,35 \%$ & 543,3 & 8,3 & 718,6 & 28,3 & 543,3 & 8,3 \\
\hline PMOG-2-1_13 & 275 & 1,05 & 15,5592 & $1,68 \%$ & 0,0595 & $1,56 \%$ & 401,5 & 6,6 & 585,8 & 33,6 & 401,5 & 6,6 \\
\hline PMOG-2-1_14 & 649 & 0,08 & 11,9550 & $1,75 \%$ & 0,0594 & $1,13 \%$ & 517,9 & 8,7 & 583,4 & 24,4 & 517,9 & 8,7 \\
\hline PMOG-2-1_15 & 78 & 0,61 & 5,8551 & $1,97 \%$ & 0,0737 & $1,59 \%$ & 1016,5 & 18,5 & 1033,6 & 31,8 & 1033,6 & 31,8 \\
\hline PMOG-2-1_16 & 243 & 0,88 & 3,9107 & $1,65 \%$ & 0,0975 & $1,10 \%$ & 1467,8 & 21,6 & 1577,8 & 20,5 & 1577,8 & 20,5 \\
\hline PMOG-2-1_17 & 990 & 0,12 & 17,6342 & $1,59 \%$ & 0,0902 & $1,21 \%$ & 355,6 & 5,5 & 1430,1 & 22,9 & 1430,1 & 5,5 \\
\hline PMOG-2-1_18 & 357 & 1,21 & 3,0457 & $1,59 \%$ & 0,1140 & $1,07 \%$ & 1830,3 & 25,2 & 1863,8 & 19,1 & 1863,8 & 19,1 \\
\hline PMOG-2-1_19 & 204 & 0,92 & 2,6854 & $1,53 \%$ & 0,1228 & $1,07 \%$ & 2040,6 & 26,7 & 1997,3 & 18,8 & 1997,3 & 18,8 \\
\hline PMOG-2-1_20 & 110 & 1,58 & 11,5151 & $1,99 \%$ & 0,0569 & $1,91 \%$ & 536,8 & 10,2 & 488,2 & 41,6 & 536,8 & 10,2 \\
\hline PMOG-2-1_21 & 92 & 0,62 & 6,0196 & $1,93 \%$ & 0,0733 & $1,73 \%$ & 990,7 & 17,7 & 1022,7 & 34,6 & 1022,7 & 34,6 \\
\hline PMOG-2-1_22 & 450 & 0,48 & 5,9404 & $1,60 \%$ & 0,0725 & $1,14 \%$ & 1003,0 & 14,9 & 1000,0 & 23,0 & 1000,0 & 23,0 \\
\hline PMOG-2-1_23 & 351 & 0,51 & 5,7406 & $1,59 \%$ & 0,0738 & $1,15 \%$ & 1035,2 & 15,2 & 1037,2 & 23,1 & 1037,2 & 23,1 \\
\hline PMOG-2-1_24 & 207 & 1,17 & 2,9412 & $1,60 \%$ & 0,1151 & $1,06 \%$ & 1886,7 & 26,1 & 1881,2 & 19,0 & 1881,2 & 19,0 \\
\hline PMOG-2-1_25 & 420 & 0,44 & 5,3273 & $2,37 \%$ & 0,0927 & $1,20 \%$ & 1109,0 & 24,1 & 1481,3 & 22,5 & 1481,3 & 22,5 \\
\hline PMOG-2-1_26 & 183 & 1,20 & 1,9190 & $1,53 \%$ & 0,2042 & $1,01 \%$ & 2703,8 & 33,8 & 2860,0 & 16,3 & 2860,0 & 16,3 \\
\hline PMOG-2-1_27 & 382 & 1,09 & 9,3467 & $1,57 \%$ & 0,0610 & $1,20 \%$ & 655,2 & 9,8 & 639,3 & 25,5 & 655,2 & 9,8 \\
\hline PMOG-2-1_28 & 61 & 1,07 & 9,4613 & $2,41 \%$ & 0,0619 & $1,96 \%$ & 647,7 & 14,8 & 671,1 & 41,4 & 647,7 & 14,8 \\
\hline PMOG-2-1_29 & 550 & 0,66 & 9,8073 & $1,69 \%$ & 0,0632 & $1,24 \%$ & 625,9 & 10,0 & 714,5 & 26,1 & 625,9 & 10,0 \\
\hline PMOG-2-1_30 & 431 & 0,50 & 15,3991 & $1,80 \%$ & 0,0571 & $1,65 \%$ & 405,6 & 7,1 & 494,7 & 35,9 & 405,6 & 7,1 \\
\hline PMOG-2-1_31 & 384 & 1,05 & 10,5936 & $1,58 \%$ & 0,0593 & $1,26 \%$ & 581,5 & 8,8 & 577,6 & 27,1 & 581,5 & 8,8 \\
\hline PMOG-2-1_32 & 571 & 0,30 & 8,7293 & $2,03 \%$ & 0,0742 & $1,79 \%$ & 699,2 & 13,5 & 1046,4 & 35,8 & 1046,4 & 13,5 \\
\hline PMOG-2-1_33 & 733 & 0,62 & 11,2048 & $1,53 \%$ & 0,0591 & $1,19 \%$ & 551,1 & 8,1 & 572,4 & 25,7 & 551,1 & 8,1 \\
\hline PMOG-2-1_34 & 254 & 0,86 & 14,8493 & $1,69 \%$ & 0,0550 & $1,61 \%$ & 420,1 & 6,9 & 413,9 & 35,5 & 420,1 & 6,9 \\
\hline PMOG-2-1_35 & 322 & 1,82 & 3,2219 & $1,58 \%$ & 0,1138 & $1,06 \%$ & 1742,6 & 24,1 & 1860,2 & 19,1 & 1860,2 & 19,1 \\
\hline PMOG-2-1_36 & 626 & 0,40 & 1,7965 & $1,52 \%$ & 0,2131 & $1,02 \%$ & 2852,8 & 35,0 & 2929,3 & 16,5 & 2929,3 & 16,5 \\
\hline PMOG-2-1_37 & 310 & 0,86 & 11,3868 & $1,69 \%$ & 0,0589 & $1,39 \%$ & 542,6 & 8,8 & 563,0 & 30,1 & 542,6 & 8,8 \\
\hline PMOG-2-1_38 & 1.621 & 0,95 & 13,8540 & $1,60 \%$ & 0,0561 & $1,12 \%$ & 449,3 & 7,0 & 456,2 & 24,6 & 449,3 & 7,0 \\
\hline PMOG-2-1_39 & 363 & 0,58 & 14,3347 & $1,78 \%$ & 0,0557 & $1,45 \%$ & 434,7 & 7,5 & 440,9 & 31,9 & 434,7 & 7,5 \\
\hline PMOG-2-1_40 & 285 & 1,01 & 10,0349 & $1,63 \%$ & 0,0595 & $1,38 \%$ & 612,4 & 9,5 & 584,0 & 29,7 & 612,4 & 9,5 \\
\hline PMOG-2-1_41 & 173 & 1,65 & 12,0906 & $1,70 \%$ & 0,0599 & $1,60 \%$ & 512,3 & 8,4 & 601,4 & 34,2 & 512,3 & 8,4 \\
\hline PMOG-2-1_42 & 388 & 2,85 & 10,2196 & $1,56 \%$ & 0,0603 & $1,25 \%$ & 601,8 & 9,0 & 613,5 & 26,9 & 601,8 & 9,0 \\
\hline PMOG-2-1_43 & 1.401 & 0,69 & 5,2723 & $1,54 \%$ & 0,1069 & $1,01 \%$ & 1119,6 & 15,8 & 1747,5 & 18,3 & 1747,5 & 18,3 \\
\hline PMOG-2-1_44 & 255 & 1,07 & 10,3793 & $1,67 \%$ & 0,0848 & $1,28 \%$ & 593,0 & 9,5 & 1310,7 & 24,6 & 1310,7 & 24,6 \\
\hline PMOG-2-1_45 & 38 & 0,78 & 6,9301 & $2,75 \%$ & 0,0733 & $2,28 \%$ & 868,9 & 22,3 & 1022,0 & 45,5 & 1022,0 & 45,5 \\
\hline PMOG-2-1_46 & 756 & 0,56 & 14,7422 & $1,46 \%$ & 0,0574 & $1,26 \%$ & 423,1 & 6,0 & 507,0 & 27,4 & 423,1 & 6,0 \\
\hline PMOG-2-1_47 & 294 & 0,62 & 4,9849 & $1,52 \%$ & 0,0802 & $1,09 \%$ & 1178,6 & 16,4 & 1201,5 & 21,4 & 1201,5 & 21,4 \\
\hline PMOG-2-1_48 & 328 & 0,61 & 7,6398 & $2,00 \%$ & 0,0734 & $1,27 \%$ & 793,0 & 14,9 & 1025,8 & 25,5 & 1025,8 & 25,5 \\
\hline PMOG-2-1_49 & 89 & 0,49 & 2,5934 & $1,84 \%$ & 0,1345 & $1,15 \%$ & 2102,4 & 33,0 & 2157,8 & 20,0 & 2157,8 & 20,0 \\
\hline PMOG-2-1_50 & 485 & 0,93 & 3,3439 & $1,52 \%$ & 0,1112 & $1,13 \%$ & 1686,6 & 22,5 & 1819,0 & 20,5 & 1819,0 & 20,5 \\
\hline PMOG-2-1_51 & 787 & 0,38 & 13,4083 & $1,68 \%$ & 0,0705 & $1,97 \%$ & 463,7 & 7,5 & 943,2 & 39,7 & 463,7 & 7,5 \\
\hline PMOG-2-1_52 & 513 & 1,27 & 9,4702 & $1,56 \%$ & 0,0633 & $1,19 \%$ & 647,1 & 9,6 & 717,2 & 25,0 & 647,1 & 9,6 \\
\hline PMOG-2-1_53 & 68 & 0,36 & 6,0416 & $1,88 \%$ & 0,0729 & $1,71 \%$ & 987,4 & 17,2 & 1011,3 & 34,4 & 1011,3 & 34,4 \\
\hline PMOG-2-1_54 & 697 & 0,59 & 14,5865 & $1,70 \%$ & 0,0556 & $1,14 \%$ & 427,5 & 7,0 & 436,8 & 25,1 & 427,5 & 7,0 \\
\hline PMOG-2-1_55 & 903 & 2,60 & 15,5433 & $1,84 \%$ & 0,0570 & $1,44 \%$ & 401,9 & 7,2 & 489,9 & 31,5 & 401,9 & 7,2 \\
\hline PMOG-2-1_56 & 698 & 1,22 & 11,4180 & $1,73 \%$ & 0,0592 & $1,19 \%$ & 541,2 & 9,0 & 573,1 & 25,7 & 541,2 & 9,0 \\
\hline PMOG-2-1_57 & 502 & 0,78 & 2,5964 & $1,55 \%$ & 0,1325 & $1,03 \%$ & 2100,3 & 27,8 & 2130,9 & 17,9 & 2130,9 & 17,9 \\
\hline PMOG-2-1_58 & 1.208 & 1,76 & 12,4553 & $1,58 \%$ & 0,0574 & $1,16 \%$ & 497,8 & 7,6 & 505,4 & 25,3 & 497,8 & 7,6 \\
\hline PMOG-2-1_59 & 306 & 0,86 & 2,6907 & $1,55 \%$ & 0,1278 & $1,04 \%$ & 2037,2 & 27,0 & 2068,2 & 18,2 & 2068,2 & 18,2 \\
\hline
\end{tabular}


Continuación TABLA 2

\begin{tabular}{|c|c|c|c|c|c|c|c|c|c|c|c|c|}
\hline $\begin{array}{c}\text { Puntos de } \\
\text { análisis }\end{array}$ & $\begin{array}{c}\mathrm{U} \\
\mathrm{ppm}\end{array}$ & $\begin{array}{c}\text { Th } \\
\text { U }\end{array}$ & $\begin{array}{l}238 \mathrm{U} / \\
206 \mathrm{~Pb}\end{array}$ & $\begin{array}{c}1 \text { sigma } \\
\text { (\% error) }\end{array}$ & $\begin{array}{l}207 \mathrm{~Pb} / \\
206 \mathrm{~Pb}\end{array}$ & $\begin{array}{c}1 \text { sigma } \\
(\% \text { error })\end{array}$ & $\begin{array}{c}\mathrm{Pb206/238U} \\
\text { (age) }\end{array}$ & $\begin{array}{c}1 \text { sigma } \\
\text { (abs err) }\end{array}$ & $\begin{array}{c}207 \mathrm{~Pb} / 206 \mathrm{~Pb} \\
\text { (age) }\end{array}$ & $\begin{array}{c}1 \text { sigma } \\
\text { (abs err) }\end{array}$ & $\begin{array}{c}\text { Best age } \\
\text { Ma }\end{array}$ & $\begin{array}{c}1 \text { sigma } \\
\text { abs err Ma }\end{array}$ \\
\hline PMOG-2-1_60 & 183 & 0,73 & 7,7466 & $1,67 \%$ & 0,0655 & $1,39 \%$ & 782,7 & 12,3 & 790,1 & 28,9 & 782,7 & 12,3 \\
\hline PMOG-2-1_61 & 1.642 & 0,07 & 6,7396 & $1,58 \%$ & 0,0759 & $0,99 \%$ & 891,9 & 13,1 & 1091,9 & 19,7 & 1091,9 & 19,7 \\
\hline PMOG-2-1_62 & 183 & 0,88 & 5,1267 & $1,60 \%$ & 0,0799 & $1,19 \%$ & 1148,7 & 16,8 & 1195,0 & 23,3 & 1195,0 & 23,3 \\
\hline PMOG-2-1_63 & 120 & 0,77 & 7,1037 & $1,71 \%$ & 0,0693 & $1,39 \%$ & 849,0 & 13,6 & 906,3 & 28,3 & 906,3 & 13,6 \\
\hline PMOG-2-1_64 & 654 & 0,06 & 1,8726 & $1,57 \%$ & 0,1993 & $0,98 \%$ & 2758,4 & 35,2 & 2820,4 & 15,9 & 2820,4 & 15,9 \\
\hline PMOG-2-1_65 & 851 & 0,18 & 7,9015 & $1,54 \%$ & 0,0660 & $1,07 \%$ & 768,2 & 11,1 & 806,5 & 22,2 & 768,2 & 11,1 \\
\hline PMOG-2-1_66 & 91 & 1,56 & 10,8296 & $1,82 \%$ & 0,0601 & $1,99 \%$ & 569,4 & 9,9 & 606,6 & 42,4 & 569,4 & 9,9 \\
\hline PMOG-2-1_67 & 524 & 0,51 & 2,7979 & $1,52 \%$ & 0,1199 & $1,02 \%$ & 1969,9 & 25,8 & 1954,0 & 18,2 & 1954,0 & 18,2 \\
\hline PMOG-2-1_68 & 167 & 0,66 & 6,3628 & $1,58 \%$ & 0,0705 & $1,29 \%$ & 941,0 & 13,8 & 941,6 & 26,3 & 941,6 & 26,3 \\
\hline PMOG-2-1_69 & 843 & 0,46 & 15,0620 & $1,59 \%$ & 0,0558 & $1,20 \%$ & 414,4 & 6,4 & 444,4 & 26,5 & 414,4 & 6,4 \\
\hline PMOG-2-1_70 & 136 & 0,53 & 8,7047 & $1,67 \%$ & 0,0709 & $1,76 \%$ & 701,0 & 11,1 & 953,9 & 35,5 & 701,0 & 11,1 \\
\hline PMOG-2-1_71 & 470 & 1,64 & 9,8213 & $1,60 \%$ & 0,0609 & $1,21 \%$ & 625,1 & 9,5 & 637,4 & 25,9 & 625,1 & 9,5 \\
\hline PMOG-2-1_72 & 1.107 & 1,99 & 14,5568 & $1,52 \%$ & 0,0594 & $1,16 \%$ & 428,3 & 6,3 & 581,2 & 25,1 & 428,3 & 6,3 \\
\hline PMOG-2-1_73 & 386 & 0,63 & 3,4320 & $1,55 \%$ & 0,1007 & $1,04 \%$ & 1648,4 & 22,5 & 1636,9 & 19,3 & 1636,9 & 19,3 \\
\hline PMOG-2-1_74 & 549 & 0,74 & 15,2827 & $1,59 \%$ & 0,0559 & $1,32 \%$ & 408,6 & 6,3 & 448,7 & 29,0 & 408,6 & 6,3 \\
\hline PMOG-2-1_75 & 514 & 0,69 & 2,5451 & $1,79 \%$ & 0,1538 & $1,13 \%$ & 2136,3 & 32,4 & 2388,4 & 19,1 & 2388,4 & 19,1 \\
\hline PMOG-2-1_76 & 123 & 0,44 & 10,7143 & $1,85 \%$ & 0,0602 & $1,76 \%$ & 575,2 & 10,1 & 609,7 & 37,6 & 575,2 & 10,1 \\
\hline PMOG-2-1_77 & 898 & 0,69 & 11,1664 & $1,68 \%$ & 0,0601 & $1,17 \%$ & 552,9 & 8,9 & 606,0 & 25,2 & 552,9 & 8,9 \\
\hline PMOG-2-1_78 & 556 & 0,25 & 13,9319 & $1,61 \%$ & 0,0613 & $1,29 \%$ & 446,9 & 7,0 & 649,9 & 27,4 & 446,9 & 7,0 \\
\hline PMOG-2-1_79 & 97 & 0,90 & 6,2448 & $1,92 \%$ & 0,0751 & $1,58 \%$ & 957,5 & 17,0 & 1070,7 & 31,4 & 1070,7 & 31,4 \\
\hline PMOG-2-1_80 & 253 & 1,10 & 2,5724 & $1,52 \%$ & 0,1407 & $1,06 \%$ & 2117,0 & 27,3 & 2236,2 & 18,2 & 2236,2 & 18,2 \\
\hline PMOG-2-1_81 & 751 & 1,45 & 14,6410 & $1,56 \%$ & 0,0644 & $1,25 \%$ & 425,9 & 6,4 & 754,7 & 26,1 & 425,9 & 6,4 \\
\hline PMOG-2-1_82 & 639 & 0,29 & 9,3865 & $1,45 \%$ & 0,0644 & $1,19 \%$ & 652,6 & 9,0 & 756,4 & 24,9 & 652,6 & 9,0 \\
\hline PMOG-2-1_83 & 91 & 0,64 & 5,6396 & $1,74 \%$ & 0,0761 & $1,59 \%$ & 1052,3 & 16,9 & 1097,6 & 31,5 & 1097,6 & 31,5 \\
\hline PMOG-2-1_84 & 248 & 0,92 & 11,2710 & $1,70 \%$ & 0,0783 & $1,37 \%$ & 548,0 & 8,9 & 1154,9 & 27,0 & 1154,9 & 8,9 \\
\hline PMOG-2-1_85 & 147 & 1,28 & 14,4550 & $1,74 \%$ & 0,0659 & $1,69 \%$ & 431,2 & 7,3 & 803,8 & 35,0 & 431,2 & 7,3 \\
\hline PMOG-2-1_86 & 332 & 0,75 & 3,1545 & $1,48 \%$ & 0,1098 & $1,04 \%$ & 1775,1 & 22,9 & 1795,5 & 18,8 & 1795,5 & 18,8 \\
\hline PMOG-2-1_87 & 453 & 0,69 & 7,8342 & $1,45 \%$ & 0,0657 & $1,09 \%$ & 774,4 & 10,6 & 797,8 & 22,6 & 774,4 & 10,6 \\
\hline PMOG-2-1_88 & 864 & 0,10 & 5,8243 & $1,45 \%$ & 0,0729 & $1,03 \%$ & 1021,4 & 13,7 & 1011,7 & 20,8 & 1011,7 & 20,8 \\
\hline PMOG-2-1_89 & 1.289 & 0,54 & 15,4017 & $2,07 \%$ & 0,0554 & $1,82 \%$ & 405,5 & 8,1 & 428,0 & 40,1 & 405,5 & 8,1 \\
\hline PMOG-2-1_90 & 346 & 0,72 & 3,8778 & $1,59 \%$ & 0,0914 & $1,05 \%$ & 1479,0 & 20,9 & 1455,3 & 19,9 & 1455,3 & 19,9 \\
\hline PMOG-2-1_91 & 1.201 & 1,32 & 14,5528 & $1,58 \%$ & 0,0549 & $1,13 \%$ & 428,4 & 6,5 & 408,9 & 25,1 & 428,4 & 6,5 \\
\hline PMOG-2-1_92 & 140 & 2,62 & 14,9946 & $1,92 \%$ & 0,0567 & $1,92 \%$ & 416,2 & 7,7 & 480,0 & 41,8 & 416,2 & 7,7 \\
\hline PMOG-2-1_93 & 836 & 0,82 & 14,9248 & $1,51 \%$ & 0,0554 & $1,18 \%$ & 418,1 & 6,1 & 429,7 & 26,1 & 418,1 & 6,1 \\
\hline PMOG-2-1_94 & 338 & 1,42 & 15,4785 & $1,86 \%$ & 0,0591 & $1,95 \%$ & 403,6 & 7,3 & 569,0 & 41,9 & 403,6 & 7,3 \\
\hline PMOG-2-1_95 & 1.851 & 0,13 & 15,5386 & $1,50 \%$ & 0,0545 & $1,08 \%$ & 402,1 & 5,8 & 389,9 & 24,2 & 402,1 & 5,8 \\
\hline PMOG-2-1_96 & 539 & 0,45 & 15,2188 & $1,59 \%$ & 0,0597 & $1,34 \%$ & 410,2 & 6,3 & 593,0 & 28,7 & 410,2 & 6,3 \\
\hline PMOG-2-1_97 & 168 & 0,51 & 5,0341 & $1,71 \%$ & 0,0819 & $1,27 \%$ & 1168,0 & 18,2 & 1244,1 & 24,6 & 1244,1 & 24,6 \\
\hline PMOG-2-1_98 & 552 & 1,24 & 15,3154 & $1,56 \%$ & 0,0553 & $1,25 \%$ & 407,7 & 6,2 & 423,2 & 27,8 & 407,7 & 6,2 \\
\hline PMOG-2-1_99 & 265 & 0,59 & 2,4224 & $1,73 \%$ & 0,1747 & $1,07 \%$ & 2227,8 & 32,6 & 2603,0 & 17,7 & 2603,0 & 17,7 \\
\hline PMOG-2-1_100 & 78 & 0,82 & 4,0776 & $2,64 \%$ & 0,1079 & $1,29 \%$ & 1413,9 & 33,5 & 1763,9 & 23,3 & 1763,9 & 23,3 \\
\hline PMOG-2-1_101 & 1.043 & 0,52 & 5,2655 & $1,82 \%$ & 0,0794 & $1,06 \%$ & 1120,9 & 18,7 & 1182,7 & 20,7 & 1182,7 & 20,7 \\
\hline PMOG-2-1_102 & 280 & 1,05 & 9,5865 & $1,65 \%$ & 0,0618 & $1,27 \%$ & 639,6 & 10,0 & 665,7 & 27,1 & 639,6 & 10,0 \\
\hline PMOG-2-1_103 & 2.131 & 0,06 & 6,8904 & $1,79 \%$ & 0,0747 & $1,01 \%$ & 873,6 & 14,6 & 1061,3 & 20,3 & 1061,3 & 20,3 \\
\hline PMOG-2-1_104 & 385 & 0,97 & 14,4252 & $1,56 \%$ & 0,0550 & $1,32 \%$ & 432,1 & 6,5 & 410,9 & 29,3 & 432,1 & 6,5 \\
\hline PMOG-2-1_105 & 97 & 2,19 & 2,7504 & $1,74 \%$ & 0,1283 & $1,18 \%$ & 1999,1 & 29,8 & 2074,9 & 20,6 & 2074,9 & 20,6 \\
\hline PMOG-2-1_106 & 149 & 0,83 & 3,1229 & $1,57 \%$ & 0,1111 & $1,11 \%$ & 1790,8 & 24,6 & 1818,1 & 20,0 & 1818,1 & 20,0 \\
\hline PMOG-2-1_107 & 1.225 & 0,40 & 11,6056 & $1,81 \%$ & 0,0745 & $1,90 \%$ & 532,8 & 9,2 & 1054,3 & 37,9 & 532,8 & 9,2 \\
\hline PMOG-2-1_108 & 176 & 0,48 & 13,6272 & $1,90 \%$ & 0,1237 & $1,84 \%$ & 456,5 & 8,4 & 2010,2 & 32,3 & 2010,2 & 32,3 \\
\hline PMOG-2-1_109 & 458 & 1,09 & 10,4544 & $1,61 \%$ & 0,0612 & $1,27 \%$ & 588,9 & 9,1 & 644,9 & 27,0 & 588,9 & 9,1 \\
\hline PMOG-2-1_110 & 413 & 0,45 & 15,1032 & $1,62 \%$ & 0,0555 & $1,32 \%$ & 413,3 & 6,5 & 431,4 & 29,1 & 413,3 & 6,5 \\
\hline PMOG-2-1_111 & 1.150 & 0,19 & 15,2860 & $1,59 \%$ & 0,0543 & $1,15 \%$ & 408,5 & 6,3 & 383,5 & 25,6 & 408,5 & 6,3 \\
\hline PMOG-2-1_112 & 594 & 0,42 & 3,9668 & $1,56 \%$ & 0,0941 & $1,05 \%$ & 1449,3 & 20,2 & 1510,4 & 19,7 & 1510,4 & 19,7 \\
\hline PMOG-2-1_113 & 711 & 0,42 & 13,8112 & $1,65 \%$ & 0,0556 & $1,22 \%$ & 450,6 & 7,2 & 438,4 & 27,0 & 450,6 & 7,2 \\
\hline PMOG-2-1_114 & 402 & 1,07 & 10,3875 & $1,71 \%$ & 0,0627 & $1,30 \%$ & 592,5 & 9,7 & 699,7 & 27,5 & 592,5 & 9,7 \\
\hline PMOG-2-1_115 & 1.044 & 0,29 & 12,0383 & $1,72 \%$ & 0,0582 & $1,12 \%$ & 514,4 & 8,5 & 537,9 & 24,3 & 514,4 & 8,5 \\
\hline PMOG-2-1_116 & 76 & 1,30 & 11,3285 & $2,40 \%$ & 0,0728 & $2,26 \%$ & 545,3 & 12,5 & 1008,8 & 45,1 & 545,3 & 12,5 \\
\hline PMOG-2-1_117 & 659 & 0,93 & 10,7844 & $1,57 \%$ & 0,0593 & $1,15 \%$ & 571,6 & 8,6 & 579,9 & 24,7 & 571,6 & 8,6 \\
\hline PMOG-2-1_118 & 241 & 0,54 & 5,9999 & $1,70 \%$ & 0,0738 & $1,25 \%$ & 993,7 & 15,6 & 1035,2 & 25,1 & 1035,2 & 25,1 \\
\hline PMOG-2-1_119 & 670 & 0,09 & 5,6211 & $1,68 \%$ & 0,0721 & $1,10 \%$ & 1055,5 & 16,3 & 988,5 & 22,2 & 988,5 & 22,2 \\
\hline PMOG-2-1_120 & 70 & 3,27 & 4,7392 & $2,04 \%$ & 0,0814 & $1,37 \%$ & 1234,2 & 22,8 & 1230,9 & 26,6 & 1230,9 & 26,6 \\
\hline
\end{tabular}


La muestra PMOG-7-1, caracterizada por la presencia de intercalaciones de capas de areniscas y lodolitas, y con desarrollo de planos de pizarrosidad tectónica, fue igualmente procesada para concentrar y datar sus zircones detríticos. Ciento diez y nueve (119) zircones detríticos fueron analizados, arrojando edades entre $369 \pm 5,4$ Ma y 2110,3 $\pm 18,1 \mathrm{Ma}$ (ver TABLA 3; FIGURA 5). Picos prominentes con edades en torno a 1750, 1181, 1039, 614, 529, 462, 416, у $372 \mathrm{Ma}$, entre otros picos menos pronunciados, se evidencian claramente entre las poblaciones de edades que arroja esta muestra (FIGURA 6). Considerando la presencia de estos picos de edades $\mathrm{U}-\mathrm{Pb}$ en zircones detríticos aquí obtenidos, es posible concluir que la máxima edad estratigráfica (máxima edad de sedimentación), es del límite Frasniense-Fameniense (Devónico Tardío), tomando como referencia el pico prominente con edades más recientes (372 Ma). No obstante, la presencia de dos (2) zircones con edades entre $371,6 \pm 5,5$ y $369,9 \pm 5,4$ (ver TABLA 3) permiten sugerir que esta unidad de roca puede tener una máxima edad de depositación Fameniense (Devónico Tardío). La presencia de zircones detríticos con picos de edades del Paleo-, Meso-, Neo-proterozoico y Cámbrico (1750, 1181, 1039, 614 y $529 \mathrm{Ma}$ ), se interpretan nuevamente como zircones detríticos procedentes principalmente de rocas fuentes más antiguas, como puede ser el caso de las unidades Gneis de Bucaramanga y Esquistos del Silgará (Cordani et al., 2005; Mantilla-Figueroa et al., 2016a, entre otros), las cuales suelen contener zircones detríticos con edades como las aquí reportadas. Por otro lado, los picos de edades 462, 416, y 372 Ma, se consideran igualmente relacionados con los diferentes eventos magmáticos del Paleozoico, resumidos en Cardona et al. (2016).
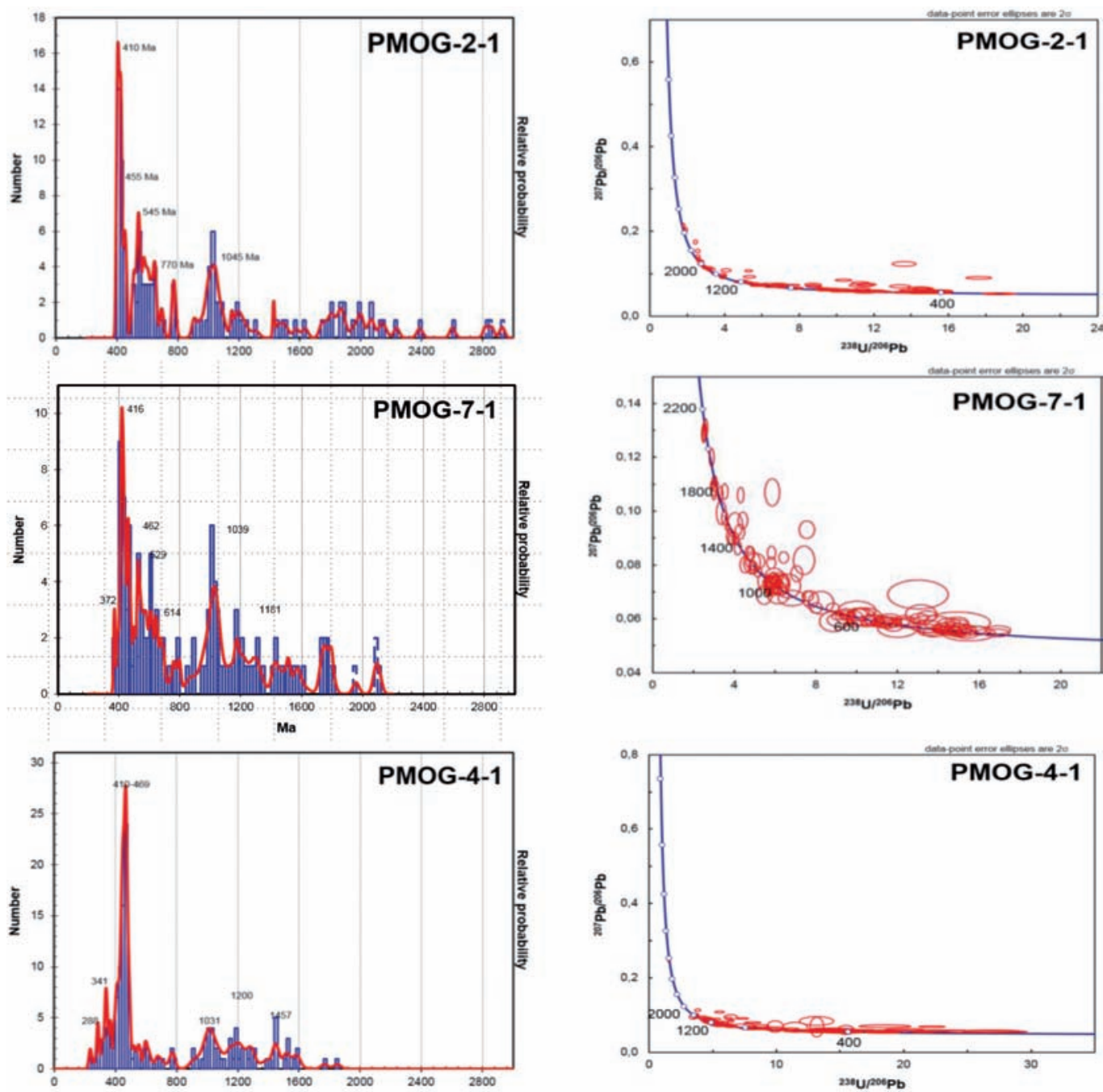

FIGURA 6. Distribución de los picos de edades obtenidas a partir del análisis de circones detríticos presentes en la muestra PMOG-2-1, PMOG-7-1 y PMOG-4-1 y sus respectivos diagramas concordia U-Pb, en los cuales se muestran las diferentes edades de los circones detríticos analizados. 
TABLA 3. Resultados analíticos U-Pb en las diferentes zonas al interior de los circones estudiados en la muestra PMOG-7-1 y sus correspondientes edades (Análisis realizados mediante la técnica LAICP-MS).

\begin{tabular}{|c|c|c|c|c|c|c|c|c|c|c|c|c|}
\hline $\begin{array}{c}\text { Puntos de } \\
\text { análisis } \\
\end{array}$ & $\begin{array}{c}\mathrm{U} \\
\mathbf{p p m} \\
\end{array}$ & $\begin{array}{l}\text { Th } \\
\mathbf{U} \\
\end{array}$ & $\begin{array}{l}238 \mathrm{U} / \\
206 \mathrm{~Pb}\end{array}$ & $\begin{array}{c}1 \text { sigma } \\
\text { (\% error) }\end{array}$ & $\begin{array}{l}207 \mathrm{~Pb} / \\
206 \mathrm{~Pb}\end{array}$ & $\begin{array}{c}1 \text { sigma } \\
\text { (\% error) }\end{array}$ & $\begin{array}{c}\mathrm{Pb206} / 238 \mathrm{U} \\
\text { (age) }\end{array}$ & $\begin{array}{r}1 \text { sigma } \\
\text { (abs err) }\end{array}$ & $\begin{array}{c}207 \mathrm{~Pb} / 206 \mathrm{~Pb} \\
\text { (age) }\end{array}$ & $\begin{array}{c}1 \text { sigma } \\
\text { (abs err) }\end{array}$ & $\begin{array}{c}\text { Best age } \\
\text { Ma }\end{array}$ & $\begin{array}{c}1 \text { sigma } \\
\text { abs err Ma }\end{array}$ \\
\hline PMOG-7-1_1 & 595 & 0,25 & 15,3605 & $1,54 \%$ & 0,0545 & $1,29 \%$ & 406,6 & 6,0 & 392,0 & 28,7 & 406,6 & 6,0 \\
\hline PMOG-7-1_2 & 875 & 0,90 & 4,3078 & $1,54 \%$ & 0,1059 & $1,11 \%$ & 1345,7 & 18,6 & 1730,5 & 20,3 & 1730,5 & 20,3 \\
\hline PMOG-7-1_3 & 1.145 & 0,63 & 13,4616 & $1,45 \%$ & 0,0611 & $1,26 \%$ & 461,9 & 6,5 & 642,9 & 27,0 & 461,9 & 6,5 \\
\hline PMOG-7-1_4 & 492 & 0,57 & 14,5300 & $1,49 \%$ & 0,0584 & $1,26 \%$ & 429,1 & 6,2 & 546,4 & 27,2 & 429,1 & 6,2 \\
\hline PMOG-7-1_5 & 60 & 0,99 & 7,7461 & $2,05 \%$ & 0,0672 & $1,92 \%$ & 782,7 & 15,1 & 844,2 & 39,3 & 782,7 & 15,1 \\
\hline PMOG-7-1_6 & 284 & 0,42 & 5,8195 & $1,55 \%$ & 0,0809 & $1,11 \%$ & 1022,2 & 14,7 & 1217,9 & 21,8 & 1217,9 & 21,8 \\
\hline PMOG-7-1_7 & 54 & 0,71 & 5,9579 & $2,19 \%$ & 0,0725 & $1,77 \%$ & 1000,2 & 20,3 & 1000,5 & 35,6 & 1000,5 & 35,6 \\
\hline PMOG-7-1_8 & 775 & 0,42 & 14,9415 & $1,53 \%$ & 0,0577 & $1,30 \%$ & 417,6 & 6,2 & 520,2 & 28,2 & 417,6 & 6,2 \\
\hline PMOG-7-1_5 & 2.270 & 0,65 & 15,9753 & $1,51 \%$ & 0,0556 & $1,06 \%$ & 391,4 & 5,7 & 438,2 & 23,5 & 391,4 & 5,7 \\
\hline PMOG-7-1_10 & 962 & 0,33 & 6,4190 & $1,54 \%$ & 0,0828 & $1,04 \%$ & 933,3 & 13,4 & 1265,1 & 20,3 & 1265,1 & 20,3 \\
\hline PMOG-7-1_11 & 376 & 0,37 & 5,8602 & $1,52 \%$ & 0,0728 & $1,11 \%$ & 1015,6 & 14,3 & 1007,1 & 22,4 & 1007,1 & 22,4 \\
\hline PMOG-7-1_12 & 1.561 & 2,51 & 16,9306 & $1,49 \%$ & 0,0559 & $1,13 \%$ & 369,9 & 5,4 & 446,9 & 25,0 & 369,9 & 5,4 \\
\hline PMOG-7-1_13 & 650 & 0,53 & 4,0700 & $1,50 \%$ & 0,0896 & $1,03 \%$ & 1416,3 & 19,0 & 1417,2 & 19,6 & 1417,2 & 19,6 \\
\hline PMOG-7-1_14 & 112 & 1,09 & 3,0251 & $1,73 \%$ & 0,1103 & $1,12 \%$ & 1841,2 & 27,7 & 1803,8 & 20,2 & 1803,8 & 20,2 \\
\hline PMOG-7-1_15 & 240 & 0,55 & 5,9250 & $1,58 \%$ & 0,0751 & $1,24 \%$ & 1005,4 & 14,7 & 1069,8 & 24,7 & 1069,8 & 24,7 \\
\hline PMOG-7-1_16 & 254 & 0,60 & 11,7247 & $1,60 \%$ & 0,0588 & $1,30 \%$ & 527,6 & 8,1 & 560,4 & 28,2 & 527,6 & 8,1 \\
\hline PMOG-7-1_17 & 247 & 0,65 & 2,5935 & $1,51 \%$ & 0,1309 & $1,04 \%$ & 2102,3 & 27,0 & 2110,3 & 18,1 & 2110,3 & 18,1 \\
\hline PMOG-7-1_18 & 463 & 0,35 & 7,5538 & $2,01 \%$ & 0,0932 & $1,44 \%$ & 801,5 & 15,1 & 1491,2 & 27,0 & 1491,2 & 27,0 \\
\hline PMOG-7-1_19 & 186 & 0,78 & 7,0543 & $1,64 \%$ & 0,0768 & $1,54 \%$ & 854,6 & 13,1 & 1115,2 & 30,5 & 1115,2 & 30,5 \\
\hline PMOG-7-1_20 & 1.838 & 0,09 & 16,8535 & $1,53 \%$ & 0,0547 & $1,06 \%$ & 371,6 & 5,5 & 401,6 & 23,7 & 371,6 & 5,5 \\
\hline PMOG-7-1_21 & 235 & 0,42 & 6,0856 & $1,47 \%$ & 0,0738 & $1,14 \%$ & 980,8 & 13,3 & 1035,0 & 22,8 & 1035,0 & 22,8 \\
\hline PMOG-7-1_22 & 103 & 1,25 & 2,8899 & $1,65 \%$ & 0,1200 & $1,15 \%$ & 1915,6 & 27,3 & 1955,7 & 20,4 & 1955,7 & 20,4 \\
\hline PMOG-7-1_23 & 157 & 1,38 & 10,8380 & $1,71 \%$ & 0,0593 & $1,53 \%$ & 568,9 & 9,3 & 579,9 & 33,0 & 568,9 & 9,3 \\
\hline PMOG-7-1_24 & 198 & 1,01 & 9,4914 & $1,64 \%$ & 0,0616 & $1,39 \%$ & 645,7 & 10,0 & 660,0 & 29,5 & 645,7 & 10,0 \\
\hline PMOG-7-1_25 & 174 & 0,51 & 4,9335 & $1,59 \%$ & 0,0791 & $1,22 \%$ & 1189,8 & 17,3 & 1173,7 & 24,0 & 1173,7 & 24,0 \\
\hline PMOG-7-1_26 & 429 & 1,07 & 8,0035 & $1,52 \%$ & 0,0640 & $1,20 \%$ & 759,0 & 10,8 & 741,3 & 25,2 & 759,0 & 10,8 \\
\hline PMOG-7-1_27 & 406 & 1,08 & 10,5685 & $1,47 \%$ & 0,0593 & $1,23 \%$ & 582,8 & 8,2 & 578,8 & 26,4 & 582,8 & 8,2 \\
\hline PMOG-7-1_28 & 482 & 1,05 & 10,7657 & $1,50 \%$ & 0,0598 & $1,17 \%$ & 572,6 & 8,2 & 595,6 & 25,0 & 572,6 & 8,2 \\
\hline PMOG-7-1_29 & 172 & 0,95 & 2,5447 & $1,52 \%$ & 0,1296 & $1,07 \%$ & 2136,6 & 27,5 & 2092,1 & 18,7 & 2092,1 & 18,7 \\
\hline PMOG-7-1_30 & 624 & 1,06 & 14,8996 & $1,50 \%$ & 0,0588 & $1,23 \%$ & 418,8 & 6,1 & 558,9 & 26,5 & 418,8 & 6,1 \\
\hline PMOG-7-1_31 & 712 & 1,46 & 12,3413 & $1,58 \%$ & 0,0595 & $1,18 \%$ & 502,3 & 7,6 & 584,2 & 25,3 & 502,3 & 7,6 \\
\hline PMOG-7-1_32 & 574 & 0,58 & 14,5758 & $2,09 \%$ & 0,0568 & $1,38 \%$ & 427,8 & 8,6 & 484,2 & 30,1 & 427,8 & 8,6 \\
\hline PMOG-7-1_33 & 484 & 0,88 & 14,1893 & $1,53 \%$ & 0,0565 & $1,39 \%$ & 439,0 & 6,5 & 470,9 & 30,4 & 439,0 & 6,5 \\
\hline PMOG-7-1_34 & 1.143 & 0,32 & 9,5097 & $1,54 \%$ & 0,0613 & $1,06 \%$ & 644,6 & 9,4 & 648,9 & 22,6 & 644,6 & 9,4 \\
\hline PMOG-7-1_35 & 366 & 0,76 & 3,3089 & $1,59 \%$ & 0,1064 & $1,04 \%$ & 1702,3 & 23,7 & 1738,3 & 19,0 & 1738,3 & 19,0 \\
\hline PMOG-7-1_36 & 417 & 0,28 & 4,8905 & $1,46 \%$ & 0,0789 & $1,09 \%$ & 1199,3 & 16,0 & 1170,2 & 21,4 & 1170,2 & 21,4 \\
\hline PMOG-7-1_37 & 872 & 0,96 & 11,7927 & $1,52 \%$ & 0,0571 & $1,11 \%$ & 524,7 & 7,7 & 493,5 & 24,3 & 524,7 & 7,7 \\
\hline PMOG-7-1_38 & 1.548 & 0,05 & 10,1824 & $1,77 \%$ & 0,0623 & $1,08 \%$ & 603,9 & 10,2 & 683,0 & 22,8 & 603,9 & 10,2 \\
\hline PMOG-7-1_39 & 152 & 0,75 & 4,8114 & $1,68 \%$ & 0,0842 & $1,22 \%$ & 1217,3 & 18,6 & 1298,0 & 23,4 & 1298,0 & 23,4 \\
\hline PMOG-7-1_40 & 745 & 0,31 & 13,7763 & $1,60 \%$ & 0,0550 & $1,22 \%$ & 451,7 & 7,0 & 410,2 & 27,0 & 451,7 & 7,0 \\
\hline PMOG-7-1_41 & 479 & 0,48 & 5,7597 & $1,64 \%$ & 0,0736 & $1,10 \%$ & 1032,0 & 15,6 & 1029,3 & 22,0 & 1029,3 & 22,0 \\
\hline PMOG-7-1_42 & 309 & 0,56 & 3,5304 & $1,64 \%$ & 0,0975 & $1,07 \%$ & 1607,7 & 23,3 & 1576,3 & 19,9 & 1576,3 & 19,9 \\
\hline PMOG-7-1_43 & 1.142 & 0,95 & 13,4997 & $1,57 \%$ & 0,0563 & $1,16 \%$ & 460,7 & 7,0 & 462,9 & 25,6 & 460,7 & 7,0 \\
\hline PMOG-7-1_44 & 2.337 & 1,64 & 14,5795 & $1,58 \%$ & 0,0560 & $1,06 \%$ & 427,7 & 6,5 & 452,7 & 23,4 & 427,7 & 6,5 \\
\hline PMOG-7-1_45 & 148 & 0,38 & 5,7419 & $1,69 \%$ & 0,0709 & $1,33 \%$ & 1035,0 & 16,1 & 956,0 & 27,1 & 956,0 & 27,1 \\
\hline PMOG-7-1_46 & 322 & 1,63 & 11,5053 & $1,75 \%$ & 0,0586 & $1,46 \%$ & 537,3 & 9,0 & 551,9 & 31,6 & 537,3 & 9,0 \\
\hline PMOG-7-1_47 & 149 & 1,03 & 5,8629 & $1,85 \%$ & 0,0737 & $1,34 \%$ & 1015,2 & 17,4 & 1034,2 & 26,9 & 1034,2 & 26,9 \\
\hline PMOG-7-1_48 & 866 & 0,44 & 14,4972 & $1,78 \%$ & 0,0555 & $1,17 \%$ & 430,0 & 7,4 & 434,3 & 25,9 & 430,0 & 7,4 \\
\hline PMOG-7-1_49 & 83 & 0,64 & 4,2737 & $2,27 \%$ & 0,0922 & $1,24 \%$ & 1355,4 & 27,7 & 1471,7 & 23,4 & 1471,7 & 23,4 \\
\hline PMOG-7-1_50 & 205 & 0,68 & 2,5100 & $1,55 \%$ & 0,1287 & $1,06 \%$ & 2161,7 & 28,4 & 2081,0 & 18,5 & 2081,0 & 18,5 \\
\hline PMOG-7-1_51 & 153 & 0,48 & 5,6357 & $1,63 \%$ & 0,0730 & $1,23 \%$ & 1053,0 & 15,8 & 1015,2 & 24,7 & 1015,2 & 24,7 \\
\hline PMOG-7-1_52 & 875 & 0,16 & 5,1655 & $1,49 \%$ & 0,0774 & $1,00 \%$ & 1140,8 & 15,6 & 1130,4 & 19,8 & 1130,4 & 19,8 \\
\hline PMOG-7-1_53 & 76 & 0,55 & 6,2439 & $1,90 \%$ & 0,0712 & $1,51 \%$ & 957,6 & 16,9 & 964,1 & 30,6 & 964,1 & 30,6 \\
\hline PMOG-7-1_54 & 132 & 0,60 & 5,8654 & $2,51 \%$ & 0,0727 & $2,33 \%$ & 1014,8 & 23,5 & 1005,2 & 46,5 & 1005,2 & 46,5 \\
\hline PMOG-7-1_55 & 655 & 1,37 & 9,1699 & $2,78 \%$ & 0,0595 & $1,78 \%$ & 667,2 & 17,6 & 586,7 & 38,2 & 667,2 & 17,6 \\
\hline PMOG-7-1_56 & 388 & 1,12 & 9,4731 & $2,09 \%$ & 0,0608 & $1,91 \%$ & 646,9 & 12,9 & 631,2 & 40,7 & 646,9 & 12,9 \\
\hline PMOG-7-1_57 & 540 & 0,05 & 6,0901 & $1,99 \%$ & 0,0723 & $1,79 \%$ & 980,1 & 18,1 & 994,5 & 35,9 & 994,5 & 35,9 \\
\hline PMOG-7-1_58 & 409 & 1,69 & 13,1566 & $2,37 \%$ & 0,0616 & $2,34 \%$ & 472,2 & 10,8 & 659,4 & 49,5 & 472,2 & 10,8 \\
\hline PMOG-7-1_59 & 134 & 0,88 & 5,8765 & $2,33 \%$ & 0,0719 & $1,57 \%$ & 1013,1 & 21,8 & 984,1 & 31,5 & 984,1 & 31,5 \\
\hline
\end{tabular}


Continuación TABLA 3

\begin{tabular}{|c|c|c|c|c|c|c|c|c|c|c|c|c|}
\hline $\begin{array}{c}\text { Puntos de } \\
\text { análisis } \\
\end{array}$ & $\begin{array}{c}\mathrm{U} \\
\mathrm{ppm}\end{array}$ & $\begin{array}{c}\text { Th } \\
\mathbf{U} \\
\end{array}$ & $\begin{array}{l}238 \mathrm{U} / \\
206 \mathrm{~Pb} \\
\end{array}$ & $\begin{array}{c}1 \text { sigma } \\
\text { (\% error) }\end{array}$ & $\begin{array}{l}207 \mathrm{~Pb} / \\
206 \mathrm{~Pb}\end{array}$ & $\begin{array}{c}1 \text { sigma } \\
\text { (\% error) }\end{array}$ & $\begin{array}{c}\begin{array}{c}\mathrm{Pb206} / 238 \mathrm{U} \\
\text { (age) }\end{array} \\
\end{array}$ & $\begin{array}{l}1 \text { sigma } \\
\text { (abs err) }\end{array}$ & $\begin{array}{c}207 \mathrm{~Pb} / 206 \mathrm{~Pb} \\
\text { (age) }\end{array}$ & $\begin{array}{c}1 \text { sigma } \\
\text { (abs err) }\end{array}$ & $\begin{array}{c}\text { Best age } \\
\text { Ma }\end{array}$ & $\begin{array}{c}1 \text { sigma } \\
\text { abs err Ma }\end{array}$ \\
\hline $\begin{array}{l}\text { PMOG-7-1_60 } \\
\end{array}$ & 276 & 0,31 & 4,5346 & $2,25 \%$ & 0,0801 & $1,60 \%$ & 1284,7 & 26,1 & 1199,4 & 31,1 & 1199,4 & 31,1 \\
\hline PMOG-7-1_61 & 539 & 0,28 & 14,9223 & $4,41 \%$ & 0,0587 & $2,71 \%$ & 418,1 & 17,8 & 554,5 & 58,0 & 418,1 & 17,8 \\
\hline PMOG-7-1_62 & 584 & 0,14 & 5,9752 & $3,02 \%$ & 0,0760 & $1,54 \%$ & 997,5 & 27,9 & 1095,3 & 30,4 & 1095,3 & 30,4 \\
\hline PMOG-7-1_63 & 594 & 0,09 & 4,0411 & $3,80 \%$ & 0,0948 & $2,00 \%$ & 1425,4 & 48,4 & 1525,1 & 37,2 & 1525,1 & 37,2 \\
\hline PMOG-7-1_64 & 299 & 0,57 & 5,0282 & $3,80 \%$ & 0,0812 & $1,55 \%$ & 1169,3 & 40,5 & 1226,7 & 30,2 & 1226,7 & 30,2 \\
\hline PMOG-7-1_65 & 1.942 & 0,25 & 4,8703 & $3,44 \%$ & 0,0807 & $2,08 \%$ & 1203,9 & 37,7 & 1214,2 & 40,5 & 1214,2 & 40,5 \\
\hline PMOG-7-1_66 & 2.185 & 1,38 & 13,0038 & $4,65 \%$ & 0,0690 & $3,14 \%$ & 477,6 & 21,4 & 899,2 & 63,5 & 477,6 & 21,4 \\
\hline PMOG-7-1_67 & 278 & 0,93 & 8,2393 & $3,05 \%$ & 0,0660 & $2,56 \%$ & 738,4 & 21,3 & 804,8 & 52,7 & 738,4 & 21,3 \\
\hline PMOG-7-1_68 & 484 & 1,26 & 5,8488 & $2,53 \%$ & 0,1070 & $1,94 \%$ & 1017,5 & 23,8 & 1749,2 & 35,2 & 1749,2 & 35,2 \\
\hline PMOG-7-1_69 & 810 & 0,33 & 3,3639 & $2,81 \%$ & 0,0995 & $1,81 \%$ & 1677,8 & 41,4 & 1614,0 & 33,3 & 1614,0 & 33,3 \\
\hline PMOG-7-1_70 & 139 & 0,96 & 6,1329 & $3,53 \%$ & 0,0728 & $1,93 \%$ & 973,7 & 31,8 & 1009,1 & 38,6 & 1009,1 & 38,6 \\
\hline PMOG-7-1_71 & 227 & 0,75 & 10,4556 & $3,10 \%$ & 0,0606 & $2,27 \%$ & 588,8 & 17,4 & 625,3 & 48,1 & 588,8 & 17,4 \\
\hline PMOG-7-1_72 & 79 & 0,62 & 5,4793 & $2,78 \%$ & 0,0688 & $2,06 \%$ & 1080,6 & 27,6 & 892,1 & 41,9 & 892,1 & 41,9 \\
\hline PMOG-7-1_73 & 1.049 & 0,16 & 15,5111 & $3,41 \%$ & 0,0546 & $2,02 \%$ & 402,8 & 13,3 & 394,3 & 44,8 & 402,8 & 13,3 \\
\hline PMOG-7-1_74 & 1.219 & 0,21 & 14,9817 & $1,63 \%$ & 0,0554 & $1,16 \%$ & 416,5 & 6,6 & 428,0 & 25,6 & 416,5 & 6,6 \\
\hline PMOG-7-1_75 & 105 & 0,67 & 3,8156 & $2,03 \%$ & 0,0905 & $1,25 \%$ & 1500,5 & 27,2 & 1437,0 & 23,7 & 1437,0 & 23,7 \\
\hline PMOG-7-1_76 & 371 & 0,34 & 15,0010 & $1,82 \%$ & 0,0561 & $1,37 \%$ & 416,0 & 7,3 & 458,0 & 30,2 & 416,0 & 7,3 \\
\hline PMOG-7-1_77 & 216 & 0,55 & 4,1689 & $1,75 \%$ & 0,0863 & $1,24 \%$ & 1386,0 & 21,8 & 1345,4 & 23,7 & 1345,4 & 23,7 \\
\hline PMOG-7-1_78 & 519 & 0,52 & 11,5896 & $2,15 \%$ & 0,0597 & $1,40 \%$ & 533,5 & 11,0 & 593,0 & 30,0 & 533,5 & 11,0 \\
\hline PMOG-7-1_79 & 220 & 0,63 & 5,8722 & $2,01 \%$ & 0,0735 & $1,22 \%$ & 1013,7 & 18,9 & 1026,5 & 24,5 & 1026,5 & 24,5 \\
\hline PMOG-7-1_80 & 236 & 1,36 & 15,0626 & $2,14 \%$ & 0,0557 & $1,75 \%$ & 414,4 & 8,6 & 439,0 & 38,5 & 414,4 & 8,6 \\
\hline PMOG-7-1_81 & 689 & 1,79 & 12,5080 & $1,99 \%$ & 0,0585 & $1,33 \%$ & 495,8 & 9,5 & 548,5 & 28,7 & 495,8 & 9,5 \\
\hline PMOG-7-1_82 & 678 & 0,96 & 11,3173 & $1,68 \%$ & 0,0589 & $1,25 \%$ & 545,8 & 8,8 & 564,3 & 27,1 & 545,8 & 8,8 \\
\hline PMOG-7-1_83 & 296 & 0,47 & 3,8900 & $1,86 \%$ & 0,0900 & $1,12 \%$ & 1474,8 & 24,4 & 1424,5 & 21,3 & 1424,5 & 21,3 \\
\hline PMOG-7-1_84 & 399 & 0,71 & 4,4313 & $2,20 \%$ & 0,0966 & $1,28 \%$ & 1311,7 & 26,1 & 1559,2 & 23,7 & 1559,2 & 23,7 \\
\hline PMOG-7-1_85 & 644 & 0,43 & 3,5364 & $1,88 \%$ & 0,1073 & $1,11 \%$ & 1605,3 & 26,7 & 1754,1 & 20,2 & 1754,1 & 20,2 \\
\hline PMOG-7-1_86 & 928 & 0,57 & 6,3631 & $1,96 \%$ & 0,0741 & $1,31 \%$ & 941,0 & 17,2 & 1045,2 & 26,3 & 1045,2 & 26,3 \\
\hline PMOG-7-1_87 & 324 & 0,57 & 6,2616 & $3,01 \%$ & 0,0730 & $2,40 \%$ & 955,1 & 26,7 & 1014,6 & 48,0 & 1014,6 & 48,0 \\
\hline PMOG-7-1_88 & 1.384 & 0,93 & 13,4700 & $2,12 \%$ & 0,0571 & $1,77 \%$ & 461,6 & 9,4 & 494,3 & 38,6 & 461,6 & 9,4 \\
\hline PMOG-7-1_89 & 801 & 0,25 & 6,8208 & $3,97 \%$ & 0,0677 & $1,74 \%$ & 881,9 & 32,6 & 859,0 & 35,7 & 859,0 & 32,6 \\
\hline PMOG-7-1_90 & 312 & 0,49 & 6,1589 & $3,57 \%$ & 0,0689 & $1,90 \%$ & 969,9 & 32,0 & 895,4 & 38,8 & 895,4 & 38,8 \\
\hline PMOG-7-1_91 & 719 & 1,05 & 11,9951 & $3,34 \%$ & 0,0566 & $2,48 \%$ & 516,2 & 16,6 & 476,7 & 53,8 & 516,2 & 16,6 \\
\hline PMOG-7-1_92 & 1.112 & 1,04 & 7,4177 & $2,77 \%$ & 0,0818 & $2,64 \%$ & 815,3 & 21,2 & 1240,0 & 50,8 & 1240,0 & 50,8 \\
\hline PMOG-7-1_93 & 109 & 0,63 & 10,0134 & $3,72 \%$ & 0,0630 & $2,28 \%$ & 613,6 & 21,8 & 707,6 & 47,8 & 613,6 & 21,8 \\
\hline PMOG-7-1_94 & 856 & 0,78 & 11,2752 & $1,90 \%$ & 0,0589 & $1,43 \%$ & 547,8 & 10,0 & 561,7 & 30,8 & 547,8 & 10,0 \\
\hline PMOG-7-1_95 & 614 & 0,20 & 10,0265 & $2,02 \%$ & 0,0615 & $1,54 \%$ & 612,9 & 11,8 & 657,1 & 32,6 & 612,9 & 11,8 \\
\hline PMOG-7-1_96 & 749 & 0,76 & 10,1974 & $2,83 \%$ & 0,0608 & $2,16 \%$ & 603,1 & 16,3 & 633,0 & 45,9 & 603,1 & 16,3 \\
\hline PMOG-7-1_97 & 81 & 0,73 & 8,8675 & $3,16 \%$ & 0,0591 & $2,62 \%$ & 688,8 & 20,6 & 569,4 & 56,1 & 688,8 & 20,6 \\
\hline PMOG-7-1_98 & 411 & 0,86 & 13,6550 & $3,43 \%$ & 0,0581 & $2,24 \%$ & 455,6 & 15,1 & 531,9 & 48,2 & 455,6 & 15,1 \\
\hline PMOG-7-1_99 & 461 & 0,54 & 5,3865 & $1,76 \%$ & 0,0740 & $1,56 \%$ & 1097,8 & 17,7 & 1042,2 & 31,2 & 1042,2 & 31,2 \\
\hline PMOG-7-1_100 & 686 & 0,85 & 2,9918 & $1,69 \%$ & 0,1083 & $1,52 \%$ & 1858,9 & 27,2 & 1770,6 & 27,6 & 1770,6 & 27,6 \\
\hline PMOG-7-1_101 & 782 & 0,25 & 13,5454 & $1,62 \%$ & 0,0551 & $1,10 \%$ & 459,2 & 7,2 & 418,1 & 24,5 & 459,2 & 7,2 \\
\hline PMOG-7-1_102 & 69 & 1,16 & 2,9902 & $1,79 \%$ & 0,1082 & $1,01 \%$ & 1859,8 & 28,9 & 1769,8 & 18,3 & 1769,8 & 18,3 \\
\hline PMOG-7-1_103 & 1.605 & 0,23 & 9,0732 & $1,29 \%$ & 0,0607 & $0,70 \%$ & 674,0 & 8,3 & 627,2 & 15,0 & 674,0 & 8,3 \\
\hline PMOG-7-1_104 & 1.140 & 0,51 & 3,6752 & $1,30 \%$ & 0,0942 & $0,60 \%$ & 1551,4 & 17,9 & 1512,1 & 11,4 & 1512,1 & 11,4 \\
\hline PMOG-7-1_105 & 692 & 1,04 & 11,0381 & $1,32 \%$ & 0,0588 & $0,81 \%$ & 559,1 & 7,1 & 558,1 & 17,6 & 559,1 & 7,1 \\
\hline PMOG-7-1_106 & 66 & 1,09 & 9,9187 & $1,76 \%$ & 0,0600 & $2,06 \%$ & 619,2 & 10,4 & 602,4 & 44,0 & 619,2 & 10,4 \\
\hline PMOG-7-1_107 & 1.188 & 0,15 & 14,9817 & $1,30 \%$ & 0,0549 & $0,83 \%$ & 416,5 & 5,2 & 406,7 & 18,4 & 416,5 & 5,2 \\
\hline PMOG-7-1_108 & 608 & 0,54 & 14,1680 & $1,26 \%$ & 0,0561 & $1,04 \%$ & 439,7 & 5,3 & 455,3 & 23,0 & 439,7 & 5,3 \\
\hline PMOG-7-1_109 & 1.646 & 0,89 & 4,9835 & $1,27 \%$ & 0,0790 & $0,63 \%$ & 1178,9 & 13,6 & 1173,1 & 12,4 & 1173,1 & 12,4 \\
\hline PMOG-7-1_110 & 315 & 1,09 & 8,8331 & $1,41 \%$ & 0,0641 & $1,01 \%$ & 691,4 & 9,2 & 745,9 & 21,3 & 691,4 & 9,2 \\
\hline PMOG-7-1_111 & 186 & 0,88 & 5,8337 & $1,43 \%$ & 0,0845 & $1,19 \%$ & 1019,9 & 13,5 & 1305,2 & 23,0 & 1305,2 & 23,0 \\
\hline PMOG-7-1_112 & 300 & 0,79 & 2,9329 & $1,37 \%$ & 0,1097 & $0,63 \%$ & 1891,3 & 22,5 & 1793,7 & 11,5 & 1793,7 & 11,5 \\
\hline PMOG-7-1_113 & 207 & 0,73 & 7,5979 & $1,38 \%$ & 0,0685 & $1,17 \%$ & 797,1 & 10,4 & 882,7 & 24,0 & 797,1 & 10,4 \\
\hline PMOG-7-1_114 & 534 & 0,38 & 14,5704 & $1,29 \%$ & 0,0561 & $1,06 \%$ & 427,9 & 5,3 & 455,2 & 23,3 & 427,9 & 5,3 \\
\hline PMOG-7-1_115 & 255 & 0,99 & 13,0605 & $1,44 \%$ & 0,0602 & $1,20 \%$ & 475,6 & 6,6 & 611,3 & 25,7 & 475,6 & 6,6 \\
\hline PMOG-7-1_116 & 25 & 0,76 & 6,6537 & $3,70 \%$ & 0,0721 & $2,56 \%$ & 902,6 & 31,1 & 989,7 & 51,3 & 989,7 & 51,3 \\
\hline PMOG-7-1_117 & 835 & 0,95 & 11,8364 & $1,32 \%$ & 0,0582 & $0,84 \%$ & 522,8 & 6,6 & 538,8 & 18,2 & 522,8 & 6,6 \\
\hline PMOG-7-1_118 & 64 & 0,65 & 4,7433 & $1,75 \%$ & 0,0843 & $1,31 \%$ & 1233,2 & 19,6 & 1300,1 & 25,3 & 1300,1 & 25,3 \\
\hline PMOG-7-1_119 & 107 & 0,39 & 5,6729 & $1,46 \%$ & 0,0741 & $1,21 \%$ & 1046,6 & 14,1 & 1043,5 & 24,2 & 1043,5 & 24,2 \\
\hline
\end{tabular}


TABLA 4. Resultados analíticos U-Pb en las diferentes zonas al interior de los circones estudiados en la muestra PMOG-4-1 y sus correspondientes edades (Análisis realizados mediante la técnica LAICP-MS).

\begin{tabular}{|c|c|c|c|c|c|c|c|c|c|c|c|c|}
\hline $\begin{array}{c}\text { Puntos de } \\
\text { análisis }\end{array}$ & $\begin{array}{c}\mathrm{U} \\
\mathrm{ppm}\end{array}$ & $\begin{array}{l}\text { Th } \\
\text { U }\end{array}$ & $\begin{array}{l}238 \mathrm{U} / \\
206 \mathrm{~Pb}\end{array}$ & $\begin{array}{c}1 \text { sigma } \\
\text { (\% error) }\end{array}$ & $\begin{array}{l}207 \mathrm{~Pb} / \\
206 \mathrm{~Pb}\end{array}$ & $\begin{array}{c}1 \text { sigma } \\
\text { (\% error) }\end{array}$ & $\begin{array}{c}\mathrm{Pb207/208U} \\
\text { (age) }\end{array}$ & $\begin{array}{l}1 \text { sigma } \\
\text { (abs err) }\end{array}$ & $\begin{array}{c}207 \mathrm{~Pb} / 208 \mathrm{U} \\
\text { (age) }\end{array}$ & $\begin{array}{l}1 \text { sigma } \\
\text { (abs err) }\end{array}$ & $\begin{array}{c}\text { Best age } \\
\text { Ma }\end{array}$ & $\begin{array}{c}\text { sigma } \\
\text { abs err Ma }\end{array}$ \\
\hline PMOG-4-1_1 & 441 & 0,39 & 14,2345 & $2,60 \%$ & 0,0559 & $1,34 \%$ & 437,7 & 11,0 & 448,0 & 29,5 & 437,7 & 11,0 \\
\hline PMOG-4-1_2 & 96 & 0,36 & 13,8829 & $2,35 \%$ & 0,0552 & $2,20 \%$ & 448,4 & 10,2 & 420,1 & 48,5 & 448,4 & 10,2 \\
\hline PMOG-4-1_3 & 134 & 0,35 & 5,9623 & $2,09 \%$ & 0,0729 & $1,37 \%$ & 999,5 & 19,3 & 1010,1 & 27,5 & 1010,1 & 27,5 \\
\hline PMOG-4-1_4 & 273 & 0,34 & 5,7198 & $1,84 \%$ & 0,0724 & $1,08 \%$ & 1038,7 & 17,6 & 998,3 & 21,8 & 998,3 & 21,8 \\
\hline PMOG-4-1_5 & 185 & 0,33 & 7,9401 & $2,05 \%$ & 0,0670 & $1,39 \%$ & 764,7 & 14,8 & 836,7 & 28,6 & 764,7 & 14,8 \\
\hline PMOG-4-1_6 & 200 & 0,25 & 5,4143 & $1,84 \%$ & 0,0762 & $1,21 \%$ & 1092,6 & 18,5 & 1101,6 & 23,9 & 1101,6 & 23,9 \\
\hline PMOG-4-1_7 & 406 & 1,07 & 13,8409 & $1,72 \%$ & 0,0590 & $4,37 \%$ & 449,7 & 7,5 & 566,1 & 92,3 & 449,7 & 7,5 \\
\hline PMOG-4-1_8 & 442 & 0,72 & 13,7304 & $2,18 \%$ & 0,0620 & $1,17 \%$ & 453,2 & 9,5 & 672,8 & 24,9 & 453,2 & 9,5 \\
\hline PMOG-4-1_9 & 574 & 0,22 & 15,9254 & $1,89 \%$ & 0,0577 & $1,22 \%$ & 392,6 & 7,2 & 519,8 & 26,6 & 392,6 & 7,2 \\
\hline PMOG-4-1_10 & 1.090 & 0,08 & 4,2396 & $1,96 \%$ & 0,0909 & $0,97 \%$ & 1365,2 & 24,1 & 1443,6 & 18,3 & 1443,6 & 18,3 \\
\hline PMOG-4-1_11 & 653 & 0,20 & 14,8972 & $1,68 \%$ & 0,0555 & $1,13 \%$ & 418,8 & 6,8 & 433,3 & 25,0 & 418,8 & 6,8 \\
\hline PMOG-4-1_12 & 549 & 0,62 & 13,2276 & $1,74 \%$ & 0,0563 & $1,25 \%$ & 469,8 & 7,9 & 465,9 & 27,4 & 469,8 & 7,9 \\
\hline PMOG-4-1_13 & 620 & 0,02 & 1,5671 & $1,65 \%$ & 0,2480 & $0,94 \%$ & 3181,5 & 41,3 & 3172,1 & 14,7 & 3172,1 & 14,7 \\
\hline PMOG-4-1_14 & 590 & 1,33 & 11,1469 & $2,17 \%$ & 0,0629 & $1,20 \%$ & 553,8 & 11,5 & 703,3 & 25,3 & 553,8 & 11,5 \\
\hline PMOG-4-1_15 & 220 & 0,55 & 5,8198 & $3,72 \%$ & 0,0752 & $1,47 \%$ & 1022,2 & 35,1 & 1073,5 & 29,2 & 1073,5 & 29,2 \\
\hline PMOG-4-1_16 & 726 & 0,34 & 3,6088 & $3,02 \%$ & 0,0954 & $1,33 \%$ & 1576,8 & 42,1 & 1535,4 & 24,9 & 1535,4 & 24,9 \\
\hline PMOG-4-1_17 & 811 & 0,32 & 13,5372 & $3,02 \%$ & 0,0610 & $1,53 \%$ & 459,4 & 13,4 & 638,4 & 32,6 & 459,4 & 13,4 \\
\hline PMOG-4-1_18 & 469 & 0,41 & 13,0979 & $2,62 \%$ & 0,0573 & $1,50 \%$ & 474,3 & 12,0 & 503,7 & 32,6 & 474,3 & 12,0 \\
\hline PMOG-4-1_19 & 291 & 0,22 & 26,8414 & $3,43 \%$ & 0,0567 & $1,77 \%$ & 235,8 & 7,9 & 478,7 & 38,7 & 235,8 & 7,9 \\
\hline PMOG-4-1_20 & 970 & 0,47 & 15,5272 & $2,68 \%$ & 0,0554 & $1,38 \%$ & 402,3 & 10,5 & 428,2 & 30,4 & 402,3 & 10,5 \\
\hline PMOG-4-1_21 & 678 & 0,29 & 5,0243 & $2,58 \%$ & 0,0812 & $1,98 \%$ & 1170,1 & 27,5 & 1227,4 & 38,5 & 1227,4 & 38,5 \\
\hline PMOG-4-1_22 & 725 & 0,14 & 12,8203 & $2,56 \%$ & 0,0562 & $1,31 \%$ & 484,2 & 11,9 & 461,6 & 28,8 & 484,2 & 11,9 \\
\hline PMOG-4-1_23 & 2.522 & 0,27 & 26,1641 & $5,47 \%$ & 0,0550 & $1,89 \%$ & 241,8 & 13,0 & 411,5 & 41,7 & 241,8 & 13,0 \\
\hline PMOG-4-1_24 & 821 & 1,52 & 13,2328 & $2,86 \%$ & 0,0566 & $1,39 \%$ & 469,6 & 12,9 & 474,3 & 30,5 & 469,6 & 12,9 \\
\hline PMOG-4-1_25 & 347 & 0,33 & 5,8973 & $3,06 \%$ & 0,0721 & $1,45 \%$ & 1009,7 & 28,5 & 989,9 & 29,1 & 989,9 & 29,1 \\
\hline PMOG-4-1_26 & 431 & 0,48 & 18,3523 & $2,92 \%$ & 0,0532 & $1,65 \%$ & 342,0 & 9,7 & 336,1 & 37,0 & 342,0 & 9,7 \\
\hline PMOG-4-1_27 & 828 & 0,39 & 13,7494 & $3,41 \%$ & 0,0620 & $2,28 \%$ & 452,6 & 14,9 & 674,4 & 48,1 & 452,6 & 14,9 \\
\hline PMOG-4-1_28 & 93 & 0,46 & 5,0640 & $4,18 \%$ & 0,0795 & $2,22 \%$ & 1161,7 & 44,3 & 1183,8 & 43,2 & 1183,8 & 43,2 \\
\hline PMOG-4-1_29 & 433 & 0,37 & 15,2565 & $3,97 \%$ & 0,0533 & $1,80 \%$ & 409,3 & 15,7 & 340,3 & 40,2 & 409,3 & 15,7 \\
\hline PMOG-4-1_30 & 84 & 0,37 & 4,4214 & $3,20 \%$ & 0,0852 & $2,56 \%$ & 1314,4 & 37,9 & 1319,5 & 48,8 & 1319,5 & 48,8 \\
\hline PMOG-4-1_31 & 539 & 0,94 & 14,3219 & $3,32 \%$ & 0,0579 & $2,32 \%$ & 435,1 & 14,0 & 527,9 & 50,0 & 435,1 & 14,0 \\
\hline PMOG-4-1_32 & 507 & 0,26 & 4,9118 & $3,36 \%$ & 0,0850 & $2,47 \%$ & 1194,6 & 36,5 & 1316,3 & 47,1 & 1316,3 & 47,1 \\
\hline PMOG-4-1_33 & 307 & 0,51 & 13,4984 & $3,80 \%$ & 0,0576 & $2,64 \%$ & 460,7 & 16,9 & 514,7 & 57,0 & 460,7 & 16,9 \\
\hline PMOG-4-1_34 & 796 & 0,22 & 15,0370 & $3,13 \%$ & 0,0603 & $1,88 \%$ & 415,1 & 12,6 & 613,2 & 40,2 & 415,1 & 12,6 \\
\hline PMOG-4-1_35 & 782 & 0,35 & 4,6770 & $3,06 \%$ & 0,0890 & $2,51 \%$ & 1249,1 & 34,7 & 1403,7 & 47,3 & 1403,7 & 47,3 \\
\hline PMOG-4-1_36 & 453 & 0,23 & 5,7999 & $2,78 \%$ & 0,0779 & $2,43 \%$ & 1025,4 & 26,3 & 1144,5 & 47,6 & 1144,5 & 47,6 \\
\hline PMOG-4-1_37 & 414 & 0,31 & 3,4645 & $3,35 \%$ & 0,0947 & $2,50 \%$ & 1634,7 & 48,1 & 1522,5 & 46,5 & 1522,5 & 46,5 \\
\hline PMOG-4-1_38 & 261 & 0,46 & 13,3549 & $3,49 \%$ & 0,0562 & $2,21 \%$ & 465,5 & 15,6 & 460,2 & 48,3 & 465,5 & 15,6 \\
\hline PMOG-4-1_39 & 998 & 0,17 & 18,5428 & $4,47 \%$ & 0,0696 & $2,02 \%$ & 338,6 & 14,7 & 916,8 & 40,9 & 338,6 & 14,7 \\
\hline PMOG-4-1_40 & 546 & 0,67 & 13,9698 & $3,03 \%$ & 0,0593 & $2,67 \%$ & 445,7 & 13,0 & 576,7 & 57,0 & 445,7 & 13,0 \\
\hline PMOG-4-1_41 & 256 & 0,35 & 13,6589 & $2,46 \%$ & 0,0572 & $2,52 \%$ & 455,5 & 10,8 & 500,7 & 54,5 & 455,5 & 10,8 \\
\hline PMOG-4-1_42 & 1.457 & 0,12 & 14,7439 & $3,15 \%$ & 0,0560 & $1,27 \%$ & 423,0 & 12,9 & 453,0 & 28,0 & 423,0 & 12,9 \\
\hline PMOG-4-1_43 & 221 & 0,49 & 4,9611 & $2,31 \%$ & 0,0786 & $1,27 \%$ & 1183,7 & 24,9 & 1162,5 & 24,9 & 1162,5 & 24,9 \\
\hline PMOG-4-1_44 & 409 & 0,44 & 18,6125 & $1,89 \%$ & 0,0541 & $1,43 \%$ & 337,4 & 6,2 & 375,2 & 31,9 & 337,4 & 6,2 \\
\hline PMOG-4-1_45 & 693 & 0,15 & 6,3456 & $2,66 \%$ & 0,0713 & $1,08 \%$ & 943,4 & 23,3 & 965,4 & 21,9 & 965,4 & 21,9 \\
\hline PMOG-4-1_46 & 1.008 & 0,08 & 4,7713 & $1,85 \%$ & 0,0781 & $1,07 \%$ & 1226,6 & 20,7 & 1150,6 & 21,1 & 1150,6 & 21,1 \\
\hline PMOG-4-1_47 & 678 & 0,06 & 6,2133 & $1,77 \%$ & 0,0913 & $1,18 \%$ & 962,0 & 15,8 & 1453,7 & 22,3 & 1453,7 & 22,3 \\
\hline PMOG-4-1_48 & 2.366 & 0,31 & 21,6343 & $2,06 \%$ & 0,0545 & $1,24 \%$ & 291,3 & 5,9 & 391,3 & 27,5 & 291,3 & 5,9 \\
\hline PMOG-4-1_49 & 919 & 0,15 & 5,2215 & $3,58 \%$ & 0,0749 & $1,38 \%$ & 1129,6 & 37,0 & 1066,0 & 27,6 & 1066,0 & 27,6 \\
\hline PMOG-4-1_50 & 2.796 & 0,91 & 13,4723 & $3,33 \%$ & 0,0570 & $1,50 \%$ & 461,6 & 14,8 & 491,1 & 32,8 & 461,6 & 14,8 \\
\hline PMOG-4-1_51 & 415 & 0,45 & 13,2431 & $2,41 \%$ & 0,0581 & $1,42 \%$ & 469,3 & 10,9 & 532,9 & 30,8 & 469,3 & 10,9 \\
\hline PMOG-4-1_52 & 347 & 0,28 & 6,4414 & $3,03 \%$ & 0,0696 & $1,61 \%$ & 930,3 & 26,2 & 917,3 & 32,8 & 917,3 & 32,8 \\
\hline PMOG-4-1_53 & 280 & 0,39 & 8,6385 & $3,93 \%$ & 0,0632 & $1,79 \%$ & 706,1 & 26,2 & 713,5 & 37,5 & 706,1 & 26,2 \\
\hline PMOG-4-1_54 & 67 & 0,33 & 5,6914 & $3,97 \%$ & 0,0742 & $2,75 \%$ & 1043,5 & 38,1 & 1047,3 & 54,5 & 1047,3 & 54,5 \\
\hline PMOG-4-1_55 & 391 & 1,45 & 9,8851 & $3,44 \%$ & 0,0629 & $2,87 \%$ & 621,2 & 20,4 & 703,5 & 59,8 & 621,2 & 20,4 \\
\hline PMOG-4-1_56 & 1.517 & 0,65 & 14,4200 & $3,65 \%$ & 0,0602 & $3,22 \%$ & 432,2 & 15,3 & 612,1 & 68,1 & 432,2 & 15,3 \\
\hline PMOG-4-1_57 & 652 & 0,03 & 11,4554 & $3,51 \%$ & 0,0668 & $7,87 \%$ & 539,5 & 18,2 & 831,1 & 156,1 & 539,5 & 18,2 \\
\hline PMOG-4-1_58 & 432 & 0,62 & 4,2969 & $3,23 \%$ & 0,0916 & $2,15 \%$ & 1348,8 & 39,2 & 1459,1 & 40,3 & 1459,1 & 40,3 \\
\hline PMOG-4-1_59 & 1.483 & 0,82 & 8,7926 & $2,85 \%$ & 0,0702 & $1,70 \%$ & 694,4 & 18,7 & 935,2 & 34,6 & 694,4 & 18,7 \\
\hline
\end{tabular}


Continuación TABLA 4

\begin{tabular}{|c|c|c|c|c|c|c|c|c|c|c|c|c|}
\hline $\begin{array}{c}\text { Puntos de } \\
\text { análisis }\end{array}$ & $\begin{array}{c}\mathrm{U} \\
\mathbf{p p m}\end{array}$ & $\begin{array}{l}\text { Th } \\
\text { U }\end{array}$ & $\begin{array}{l}238 \mathrm{U} / \\
206 \mathrm{~Pb}\end{array}$ & $\begin{array}{c}1 \text { sigma } \\
\text { (abs err) }\end{array}$ & $\begin{array}{l}207 \mathrm{~Pb} / \\
206 \mathrm{~Pb}\end{array}$ & $\begin{array}{c}1 \text { sigma } \\
\text { (abs err) }\end{array}$ & $\begin{array}{c}\mathrm{Pb207/208U} \\
\text { (age) }\end{array}$ & $\begin{array}{c}1 \text { sigma } \\
\text { (abs err) }\end{array}$ & $\begin{array}{c}207 \mathrm{~Pb} / 208 \mathrm{U} \\
\text { (age) }\end{array}$ & $\begin{array}{c}1 \text { sigma } \\
\text { (abs err) }\end{array}$ & $\begin{array}{c}\text { Best age } \\
\mathrm{Ma}\end{array}$ & $\begin{array}{c}\text { sigma } \\
\text { abs err Ma }\end{array}$ \\
\hline$\overline{\text { PMOG-4-1_60 }}$ & 414 & 0,17 & 8,1554 & $3,20 \%$ & 0,0798 & $1,28 \%$ & 745,6 & 22,5 & 1192,9 & 25,1 & 1192,9 & 25,1 \\
\hline PMOG-4-1_61 & 618 & 0,19 & 15,4362 & $1,78 \%$ & 0,0600 & $8,36 \%$ & 404,6 & 7,0 & 603,2 & 171,4 & 404,6 & 7,0 \\
\hline PMOG-4-1_62 & 2.374 & 0,42 & 18,4559 & $2,36 \%$ & 0,0582 & $1,23 \%$ & 340,2 & 7,8 & 538,4 & 26,7 & 340,2 & 7,8 \\
\hline PMOG-4-1_63 & 505 & 0,33 & 3,8206 & $2,18 \%$ & 0,1132 & $1,27 \%$ & 1498,7 & 29,1 & 1851,0 & 22,8 & 1851,0 & 22,8 \\
\hline PMOG-4-1_64 & 543 & 0,78 & 12,9997 & $2,13 \%$ & 0,0578 & $1,39 \%$ & 477,7 & 9,8 & 521,5 & 30,2 & 477,7 & 9,8 \\
\hline PMOG-4-1_65 & 596 & 0,13 & 5,6419 & $1,99 \%$ & 0,0779 & $1,18 \%$ & 1051,9 & 19,2 & 1144,6 & 23,3 & 1144,6 & 23,3 \\
\hline PMOG-4-1_66 & 228 & 0,30 & 15,3502 & $1,70 \%$ & 0,0561 & $1,25 \%$ & 406,8 & 6,7 & 457,7 & 27,5 & 406,8 & 6,7 \\
\hline PMOG-4-1_67 & 3.522 & 0,48 & 22,8427 & $3,67 \%$ & 0,0589 & $0,88 \%$ & 276,2 & 9,9 & 562,8 & 19,0 & 276,2 & 9,9 \\
\hline PMOG-4-1_68 & 390 & 0,57 & 13,1771 & $1,56 \%$ & 0,0560 & $1,11 \%$ & 471,5 & 7,1 & 454,2 & 24,5 & 471,5 & 7,1 \\
\hline PMOG-4-1_69 & 392 & 0,56 & 11,9331 & $1,51 \%$ & 0,0583 & $1,50 \%$ & 518,8 & 7,5 & 541,3 & 32,5 & 518,8 & 7,5 \\
\hline PMOG-4-1_70 & 2.653 & 0,64 & 13,8446 & $1,46 \%$ & 0,0566 & $0,86 \%$ & 449,6 & 6,3 & 474,8 & 18,9 & 449,6 & 6,3 \\
\hline PMOG-4-1_71 & 2.918 & 0,47 & 22,2180 & $1,89 \%$ & 0,0684 & $1,01 \%$ & 283,8 & 5,2 & 882,1 & 20,7 & 283,8 & 5,2 \\
\hline PMOG-4-1_72 & 1.594 & 0,12 & 13,2580 & $1,51 \%$ & 0,0566 & $0,85 \%$ & 468,8 & 6,8 & 475,3 & 18,7 & 468,8 & 6,8 \\
\hline PMOG-4-1_73 & 4.573 & 0,27 & 17,0674 & $1,55 \%$ & 0,0599 & $0,85 \%$ & 367,1 & 5,5 & 599,8 & 18,2 & 367,1 & 5,5 \\
\hline PMOG-4-1_74 & 272 & 0,25 & 6,4136 & $1,82 \%$ & 0,0833 & $0,96 \%$ & 934,1 & 15,8 & 1277,0 & 18,6 & 1277,0 & 18,6 \\
\hline PMOG-4-1_75 & 2.707 & 0,25 & 17,9715 & $1,70 \%$ & 0,0553 & $0,86 \%$ & 349,1 & 5,8 & 426,4 & 19,0 & 349,1 & 5,8 \\
\hline PMOG-4-1_76 & 471 & 0,76 & 13,7841 & $1,55 \%$ & 0,0571 & $1,05 \%$ & 451,5 & 6,7 & 496,2 & 23,0 & 451,5 & 6,7 \\
\hline PMOG-4-1_77 & 230 & 0,42 & 13,3806 & $1,79 \%$ & 0,0590 & $1,27 \%$ & 464,6 & 8,0 & 565,6 & 27,3 & 464,6 & 8,0 \\
\hline PMOG-4-1_78 & 1.625 & 0,19 & 18,4797 & $1,76 \%$ & 0,0557 & $0,95 \%$ & 339,7 & 5,8 & 441,8 & 21,0 & 339,7 & 5,8 \\
\hline PMOG-4-1_79 & 1.368 & 0,41 & 14,1807 & $1,77 \%$ & 0,0564 & $0,94 \%$ & 439,3 & 7,5 & 468,4 & 20,7 & 439,3 & 7,5 \\
\hline PMOG-4-1_80 & 2.741 & 0,22 & 17,1349 & $1,93 \%$ & 0,0574 & $0,89 \%$ & 365,6 & 6,9 & 506,4 & 19,4 & 365,6 & 6,9 \\
\hline PMOG-4-1_81 & 915 & 0,27 & 13,4334 & $1,66 \%$ & 0,0560 & $0,93 \%$ & 462,9 & 7,4 & 451,8 & 20,6 & 462,9 & 7,4 \\
\hline PMOG-4-1_82 & 2.490 & 0,31 & 16,0550 & $1,60 \%$ & 0,0595 & $0,87 \%$ & 389,5 & 6,0 & 585,5 & 18,7 & 389,5 & 6,0 \\
\hline PMOG-4-1_83 & 197 & 0,52 & 12,4483 & $2,09 \%$ & 0,0563 & $1,40 \%$ & 498,1 & 10,0 & 462,3 & 30,6 & 498,1 & 10,0 \\
\hline PMOG-4-1_84 & 494 & 0,29 & 13,0932 & $1,69 \%$ & 0,0572 & $1,09 \%$ & 474,5 & 7,7 & 498,6 & 23,9 & 474,5 & 7,7 \\
\hline PMOG-4-1_85 & 3.030 & 0,84 & 16,8478 & $1,96 \%$ & 0,0597 & $0,89 \%$ & 371,7 & 7,1 & 594,4 & 19,3 & 371,7 & 7,1 \\
\hline PMOG-4-1_86 & 205 & 0,42 & 12,6741 & $1,61 \%$ & 0,0558 & $1,31 \%$ & 489,6 & 7,6 & 445,7 & 28,9 & 489,6 & 7,6 \\
\hline PMOG-4-1_87 & 440 & 0,31 & 13,2962 & $1,79 \%$ & 0,0558 & $1,10 \%$ & 467,5 & 8,1 & 444,7 & 24,2 & 467,5 & 8,1 \\
\hline PMOG-4-1_88 & 3.589 & 0,41 & 19,9434 & $2,07 \%$ & 0,0579 & $0,91 \%$ & 315,4 & 6,4 & 525,0 & 19,9 & 315,4 & 6,4 \\
\hline PMOG-4-1_89 & 350 & 0,38 & 13,6586 & $1,78 \%$ & 0,0569 & $1,09 \%$ & 455,5 & 7,8 & 489,3 & 23,8 & 455,5 & 7,8 \\
\hline PMOG-4-1_90 & 500 & 0,38 & 13,1715 & $1,68 \%$ & 0,0679 & $15,75 \%$ & 471,7 & 7,7 & 865,0 & 296,5 & 471,7 & 7,7 \\
\hline PMOG-4-1_91 & 516 & 0,52 & 14,2090 & $1,58 \%$ & 0,0567 & $1,10 \%$ & 438,4 & 6,7 & 481,5 & 24,1 & 438,4 & 6,7 \\
\hline PMOG-4-1_92 & 267 & 0,36 & 14,0213 & $1,70 \%$ & 0,0558 & $1,18 \%$ & 444,1 & 7,3 & 442,6 & 26,1 & 444,1 & 7,3 \\
\hline PMOG-4-1_93 & 259 & 0,40 & 12,6957 & $1,66 \%$ & 0,0563 & $1,28 \%$ & 488,8 & 7,8 & 463,4 & 28,1 & 488,8 & 7,8 \\
\hline PMOG-4-1_94 & 1.212 & 0,33 & 14,2812 & $2,42 \%$ & 0,0592 & $0,92 \%$ & 436,3 & 10,2 & 575,3 & 19,8 & 436,3 & 10,2 \\
\hline PMOG-4-1_95 & 140 & 0,35 & 13,2605 & $1,69 \%$ & 0,0561 & $1,55 \%$ & 468,7 & 7,6 & 456,5 & 34,0 & 468,7 & 7,6 \\
\hline PMOG-4-1_96 & 289 & 0,26 & 4,3520 & $1,42 \%$ & 0,0944 & $0,86 \%$ & 1333,3 & 17,1 & 1516,0 & 16,1 & 1516,0 & 16,1 \\
\hline PMOG-4-1_97 & 303 & 0,37 & 12,5519 & $1,65 \%$ & 0,0575 & $1,10 \%$ & 494,1 & 7,8 & 510,8 & 23,9 & 494,1 & 7,8 \\
\hline PMOG-4-1_98 & 477 & 0,33 & 13,1946 & $1,75 \%$ & 0,0571 & $1,11 \%$ & 470,9 & 7,9 & 495,9 & 24,2 & 470,9 & 7,9 \\
\hline PMOG-4-1_99 & 443 & 0,74 & 12,9827 & $1,53 \%$ & 0,0573 & $1,13 \%$ & 478,3 & 7,1 & 503,1 & 24,8 & 478,3 & 7,1 \\
\hline PMOG-4-1_100 & 380 & 0,31 & 12,6237 & $1,85 \%$ & 0,0566 & $1,18 \%$ & 491,4 & 8,8 & 477,1 & 25,9 & 491,4 & 8,8 \\
\hline PMOG-4-1_101 & 373 & 0,35 & 12,9631 & $1,92 \%$ & 0,0571 & $1,08 \%$ & 479,0 & 8,9 & 493,9 & 23,7 & 479,0 & 8,9 \\
\hline PMOG-4-1_102 & 421 & 0,40 & 4,9779 & $5,37 \%$ & 0,0796 & $1,58 \%$ & 1180,1 & 57,6 & 1186,1 & 30,9 & 1186,1 & 30,9 \\
\hline PMOG-4-1_103 & 94 & 0,48 & 5,6392 & $2,87 \%$ & 0,0729 & $1,73 \%$ & 1052,4 & 27,8 & 1010,7 & 34,8 & 1010,7 & 34,8 \\
\hline PMOG-4-1_104 & 184 & 0,27 & 5,3643 & $4,54 \%$ & 0,0756 & $2,43 \%$ & 1101,9 & 45,8 & 1084,1 & 48,0 & 1084,1 & 48,0 \\
\hline PMOG-4-1_105 & 132 & 0,20 & 7,4648 & $5,01 \%$ & 0,0702 & $3,08 \%$ & 810,4 & 38,1 & 934,4 & 61,9 & 934,4 & 38,1 \\
\hline PMOG-4-1_106 & 173 & 0,32 & 10,0743 & $3,18 \%$ & 0,0624 & $2,85 \%$ & 610,1 & 18,5 & 686,9 & 59,6 & 610,1 & 18,5 \\
\hline PMOG-4-1_107 & 328 & 0,23 & 3,6537 & $3,05 \%$ & 0,0972 & $2,56 \%$ & 1559,5 & 42,1 & 1571,2 & 47,2 & 1571,2 & 47,2 \\
\hline PMOG-4-1_108 & 299 & 0,11 & 5,3907 & $2,82 \%$ & 0,0736 & $2,65 \%$ & 1097,0 & 28,4 & 1029,4 & 52,6 & 1029,4 & 52,6 \\
\hline PMOG-4-1_109 & 416 & 0,31 & 14,2207 & $3,47 \%$ & 0,0591 & $2,40 \%$ & 438,1 & 14,7 & 572,5 & 51,4 & 438,1 & 14,7 \\
\hline PMOG-4-1_110 & 1.169 & 0,14 & 21,8123 & $3,17 \%$ & 0,0563 & $1,19 \%$ & 289,0 & 8,9 & 463,7 & 26,1 & 289,0 & 8,9 \\
\hline PMOG-4-1_111 & 127 & 0,25 & 5,9538 & $2,30 \%$ & 0,0735 & $1,16 \%$ & 1000,9 & 21,3 & 1028,3 & 23,3 & 1028,3 & 23,3 \\
\hline PMOG-4-1_112 & 428 & 0,17 & 10,2863 & $2,11 \%$ & 0,0612 & $1,16 \%$ & 598,1 & 12,0 & 645,1 & 24,7 & 598,1 & 12,0 \\
\hline PMOG-4-1_113 & 645 & 0,24 & 13,2267 & $1,87 \%$ & 0,0568 & $1,08 \%$ & 469,8 & 8,5 & 483,2 & 23,7 & 469,8 & 8,5 \\
\hline PMOG-4-1_114 & 139 & 0,37 & 5,9537 & $2,20 \%$ & 0,0724 & $1,35 \%$ & 1000,9 & 20,4 & 996,6 & 27,1 & 996,6 & 27,1 \\
\hline PMOG-4-1_115 & 406 & 0,25 & 4,7959 & $2,97 \%$ & 0,0811 & $1,18 \%$ & 1220,9 & 32,9 & 1223,0 & 23,0 & 1223,0 & 23,0 \\
\hline PMOG-4-1_116 & 519 & 0,27 & 5,5236 & $2,70 \%$ & 0,1081 & $1,24 \%$ & 1072,7 & 26,6 & 1768,3 & 22,5 & 1768,3 & 22,5 \\
\hline PMOG-4-1_117 & 221 & 0,17 & 4,9647 & $1,61 \%$ & 0,0807 & $1,07 \%$ & 1182,9 & 17,4 & 1213,4 & 20,9 & 1213,4 & 20,9 \\
\hline PMOG-4-1_118 & 289 & 0,18 & 9,0978 & $2,07 \%$ & 0,0624 & $1,22 \%$ & 672,3 & 13,2 & 686,4 & 25,8 & 672,3 & 13,2 \\
\hline PMOG-4-1_119 & 106 & 0,34 & 5,7977 & $2,09 \%$ & 0,0731 & $1,19 \%$ & 1025,8 & 19,8 & 1018,0 & 23,8 & 1018,0 & 23,8 \\
\hline PMOG-4-1_120 & 558 & 0,17 & 17,9308 & $3,17 \%$ & 0,0554 & $1,86 \%$ & 349,8 & 10,8 & 428,9 & 40,9 & 349,8 & 10,8 \\
\hline
\end{tabular}


Continuación TABLA 4

\begin{tabular}{|c|c|c|c|c|c|c|c|c|c|c|c|c|}
\hline $\begin{array}{l}\text { Puntos de } \\
\text { análisis }\end{array}$ & $\begin{array}{c}\mathrm{U} \\
\mathrm{ppm}\end{array}$ & $\begin{array}{l}\text { Th } \\
\text { U }\end{array}$ & $\begin{array}{l}238 \mathrm{U} / \\
206 \mathrm{~Pb}\end{array}$ & $\begin{array}{c}1 \text { sigma } \\
\text { (abs err) }\end{array}$ & $\begin{array}{l}207 \mathrm{~Pb} / \\
206 \mathrm{~Pb}\end{array}$ & $\begin{array}{c}1 \text { sigma } \\
\text { (abs err) }\end{array}$ & $\begin{array}{c}\mathrm{Pb207/208U} \\
\text { (age) }\end{array}$ & $\begin{array}{c}1 \text { sigma } \\
\text { (abs err) }\end{array}$ & $\begin{array}{c}207 \mathrm{~Pb} / 208 \mathrm{U} \\
\text { (age) }\end{array}$ & $\begin{array}{c}1 \text { sigma } \\
\text { (abs err) }\end{array}$ & $\begin{array}{c}\text { Best age } \\
\text { Ma }\end{array}$ & $\begin{array}{c}\text { sigma } \\
\text { abs err Ma }\end{array}$ \\
\hline$\overline{\text { PMOG-4-1_121 }}$ & 98 & 0,38 & 6,4055 & $3,20 \%$ & 0,0951 & $2,55 \%$ & 935,1 & 27,8 & 1529,6 & 47,2 & 1529,6 & 47,2 \\
\hline PMOG-4-1_122 & 505 & 0,48 & 20,0235 & $3,12 \%$ & 0,0607 & $2,38 \%$ & 314,2 & 9,6 & 628,4 & 50,5 & 314,2 & 9,6 \\
\hline PMOG-4-1_123 & 165 & 0,68 & 13,9110 & $2,73 \%$ & 0,0573 & $1,70 \%$ & 447,5 & 11,8 & 502,1 & 37,0 & 447,5 & 11,8 \\
\hline PMOG-4-1_124 & 489 & 0,63 & 13,5214 & $3,06 \%$ & 0,0595 & $1,89 \%$ & 460,0 & 13,6 & 585,0 & 40,5 & 460,0 & 13,6 \\
\hline PMOG-4-1_125 & 275 & 0,84 & 10,3566 & $1,68 \%$ & 0,0596 & $1,10 \%$ & 594,2 & 9,5 & 588,4 & 23,7 & 594,2 & 9,5 \\
\hline PMOG-4-1_126 & 593 & 0,27 & 4,7627 & $1,96 \%$ & 0,0913 & $0,95 \%$ & 1228,6 & 21,9 & 1452,9 & 18,0 & 1452,9 & 18,0 \\
\hline PMOG-4-1_127 & 218 & 0,33 & 4,8622 & $1,87 \%$ & 0,0840 & $1,07 \%$ & 1205,7 & 20,6 & 1293,5 & 20,6 & 1293,5 & 20,6 \\
\hline PMOG-4-1_128 & 312 & 0,99 & 14,7562 & $2,10 \%$ & 0,0564 & $1,36 \%$ & 422,7 & 8,6 & 468,7 & 29,7 & 422,7 & 8,6 \\
\hline PMOG-4-1_129 & 34 & 0,65 & 9,9103 & $2,65 \%$ & 0,0689 & $9,09 \%$ & 619,7 & 15,6 & 894,6 & 177,1 & 619,7 & 15,6 \\
\hline PMOG-4-1_130 & 535 & 0,44 & 13,4436 & $1,81 \%$ & 0,0566 & $1,17 \%$ & 462,5 & 8,1 & 474,1 & 25,6 & 462,5 & 8,1 \\
\hline PMOG-4-1_132 & 199 & 0,39 & 13,4049 & $2,00 \%$ & 0,0569 & $1,42 \%$ & 463,8 & 8,9 & 489,1 & 31,1 & 463,8 & 8,9 \\
\hline PMOG-4-1_133 & 319 & 0,25 & 5,0493 & $1,94 \%$ & 0,0823 & $1,09 \%$ & 1164,8 & 20,6 & 1252,4 & 21,2 & 1252,4 & 21,2 \\
\hline PMOG-4-1_134 & 249 & 0,50 & 13,1906 & $1,78 \%$ & 0,0580 & $1,42 \%$ & 471,1 & 8,1 & 530,3 & 30,8 & 471,1 & 8,1 \\
\hline PMOG-4-1_135 & 135 & 0,38 & 3,5856 & $1,99 \%$ & 0,0982 & $1,12 \%$ & 1585,8 & 27,9 & 1590,2 & 20,8 & 1590,2 & 20,8 \\
\hline PMOG-4-1_136 & 234 & 0,30 & 5,1784 & $1,93 \%$ & 0,0800 & $1,08 \%$ & 1138,2 & 20,1 & 1198,0 & 21,2 & 1198,0 & 21,2 \\
\hline PMOG-4-1_137 & 244 & 0,43 & 15,2110 & $1,98 \%$ & 0,0584 & $1,41 \%$ & 410,5 & 7,9 & 543,4 & 30,5 & 410,5 & 7,9 \\
\hline PMOG-4-1_138 & 536 & 0,31 & 13,8245 & $1,86 \%$ & 0,0560 & $1,19 \%$ & 450,2 & 8,1 & 451,5 & 26,2 & 450,2 & 8,1 \\
\hline PMOG-4-1_139 & 197 & 0,13 & 3,6471 & $2,03 \%$ & 0,0981 & $1,19 \%$ & 1562,0 & 28,1 & 1587,9 & 22,1 & 1587,9 & 22,1 \\
\hline PMOG-4-1_140 & 359 & 0,30 & 11,0868 & $1,84 \%$ & 0,0568 & $1,28 \%$ & 556,7 & 9,8 & 482,6 & 28,0 & 556,7 & 9,8 \\
\hline PMOG-4-1_141 & 2.804 & 0,46 & 14,6020 & $2,76 \%$ & 0,0572 & $1,08 \%$ & 427,0 & 11,4 & 499,4 & 23,7 & 427,0 & 11,4 \\
\hline PMOG-4-1_143 & 256 & 0,19 & 5,4014 & $1,99 \%$ & 0,0744 & $1,25 \%$ & 1095,0 & 20,0 & 1052,8 & 24,9 & 1052,8 & 24,9 \\
\hline PMOG-4-1_144 & 158 & 0,22 & 6,4574 & $1,98 \%$ & 0,0696 & $1,30 \%$ & 928,2 & 17,1 & 916,9 & 26,6 & 916,9 & 26,6 \\
\hline PMOG-4-1_145 & 1.924 & 0,07 & 7,7663 & $1,68 \%$ & 0,0685 & $1,13 \%$ & 780,8 & 12,4 & 883,5 & 23,1 & 780,8 & 12,4 \\
\hline PMOG-4-1_146 & 718 & 0,16 & 7,3352 & $2,58 \%$ & 0,0909 & $1,11 \%$ & 823,9 & 19,9 & 1443,7 & 21,1 & 1443,7 & 21,1 \\
\hline PMOG-4-1_147 & 258 & 0,59 & 5,2809 & $2,41 \%$ & 0,0883 & $1,24 \%$ & 1117,9 & 24,7 & 1389,9 & 23,6 & 1389,9 & 23,6 \\
\hline PMOG-4-1_148 & 110 & 0,38 & 5,6328 & $1,87 \%$ & 0,0730 & $1,31 \%$ & 1053,5 & 18,2 & 1013,0 & 26,4 & 1013,0 & 26,4 \\
\hline PMOG-4-1_149 & 437 & 0,30 & 13,5438 & $1,82 \%$ & 0,0566 & $1,14 \%$ & 459,2 & 8,1 & 476,6 & 24,9 & 459,2 & 8,1 \\
\hline PMOG-4-1_150 & 658 & 0,73 & 13,3454 & $2,12 \%$ & 0,0561 & $1,14 \%$ & 465,8 & 9,5 & 457,0 & 25,2 & 465,8 & 9,5 \\
\hline PMOG-4-1_151 & 77 & 0,45 & 4,5517 & $1,88 \%$ & 0,0825 & $1,34 \%$ & 1280,3 & 21,8 & 1258,3 & 26,0 & 1258,3 & 26,0 \\
\hline PMOG-4-1_152 & 618 & 0,18 & 13,9467 & $1,75 \%$ & 0,0559 & $1,05 \%$ & 446,4 & 7,5 & 449,5 & 23,1 & 446,4 & 7,5 \\
\hline PMOG-4-1_153 & 108 & 0,35 & 11,6556 & $2,46 \%$ & 0,0581 & $1,62 \%$ & 530,6 & 12,5 & 532,5 & 35,1 & 530,6 & 12,5 \\
\hline PMOG-4-1_154 & 159 & 0,42 & 18,9363 & $2,00 \%$ & 0,0549 & $1,80 \%$ & 331,7 & 6,5 & 408,0 & 39,7 & 331,7 & 6,5 \\
\hline PMOG-4-1_156 & 212 & 0,29 & 5,5141 & $1,78 \%$ & 0,0736 & $1,25 \%$ & 1074,4 & 17,6 & 1030,6 & 25,0 & 1030,6 & 25,0 \\
\hline PMOG-4-1_157 & 47 & 0,31 & 6,2856 & $2,15 \%$ & 0,0734 & $1,72 \%$ & 951,7 & 19,0 & 1026,1 & 34,4 & 1026,1 & 34,4 \\
\hline PMOG-4-1_158 & 24 & 0,98 & 7,8916 & $3,64 \%$ & 0,0643 & $2,48 \%$ & 769,1 & 26,4 & 750,4 & 51,6 & 769,1 & 26,4 \\
\hline PMOG-4-1_159 & 401 & 0,52 & 13,1345 & $4,15 \%$ & 0,0842 & $5,77 \%$ & 473,0 & 18,9 & 1298,0 & 108,2 & 1298,0 & 18,9 \\
\hline
\end{tabular}

La muestra PMOG-4-1 es una roca lodolítica de color gris oscuro a negro (debido a la presencia de materia orgánica). Ciento cincuenta y nueve (159) análisis fueron realizados en zircones detríticos presentes en ésta muestra, arrojando edades entre $235,8 \pm 7,9 \mathrm{Ma}$ y $3172,1 \pm 14,7 \mathrm{Ma}$ (ver TABLA 4, FIGURA 5). Picos prominentes con edades en torno a 1457, 1200, 1031, 469, 410, 431 y $288 \mathrm{Ma}$, entre otros picos menos pronunciados, se evidencian claramente entre las poblaciones de edades que arroja esta muestra (FIGURA 6). Considerando las edades U-Pb en zircones detríticos aquí obtenidas, es posible concluir que la máxima edad estratigráfica (máxima edad de sedimentación del protolito), es Artinskiense (Cisuraliense, Pérmico), tomando como referencia el pico prominente con edades más recientes (288 Ma). La presencia de zircones detríticos con picos de edades del Meso-, Neo-proterozoico y Cámbrico (1457, 1200, 1031, 469, 410, 431 y $288 \mathrm{Ma}$ ), se interpretan nuevamente como zircones detríticos procedentes principalmente del desmantelamiento de rocas más antiguas presentes en el Macizo de Santander, tales como las unidades Gneis de Bucaramanga, Esquistos del Silgará, Esquistos del Chicamocha, Ortogneis, Filitas de San Pedro (las cuales presentan zircones detríticos antiguos como los aquí mencionados), como también de rocas ígneas Paleozoicas (entre otros en Cordani et al., 2005; Mantilla-Figueroa et al., 2016a; Cardona et al., 2016; García-Ramírez et al., 2017).

\section{IMPLICACIONES GEOLÓGICAS}

Desde los primeros estudios de cartografía geológica realizados en el Macizo de Santander (Ward et al., 1973), se menciona la presencia de rocas sedimentarias de edad Devónico afectadas localmente por metamorfismo. Esta característica en rocas de esta edad, muy seguramente suscitó lo que actualmente se relaciona en la bibliografía como Formación Floresta con y sin metamorfismo (según cada caso). Sin embargo, el tipo de metamorfismo 
con el cual se relaciona esta formación no es nada claro (¿regional/ dinamo-térmico/de enterramiento/ hidrotermal/de contacto?). Si a este hecho sumamos la posible confusión que puede generar la presencia de otras rocas de bajo grado de metamorfismo en el MS (por ejemplo, filitas de las unidades Esquistos de Silgará s.l., Filitas de San Pedro, metasedimentitas de la Virgen, las metasedimentitas de Guaca, entre otras; Ward et al., 1973; Vargas et al., 1981; Royero y Clavijo, 2001; Clavijo et al., 2008; Mantilla-Figueroa et al., 2016a; 2016b), resulta evidente la imperiosa necesidad de profundizar en el conocimiento de éstas litologías con metamorfismo de muy bajo y bajo grado. Esto, no tanto para resolver inmediatamente aspectos puramente cartográficos (resulta algo inalcanzable por ahora, considerando que aún se requiere más información sobre la edad y la variedad composicional de estas rocas de bajo grado en el MS), sino más bien para empezar a esclarecer (al menos por sectores) las relaciones entre estas litologías relativamente muy similares, pero en edad y tipo de metamorfismo posiblemente muy diferentes.

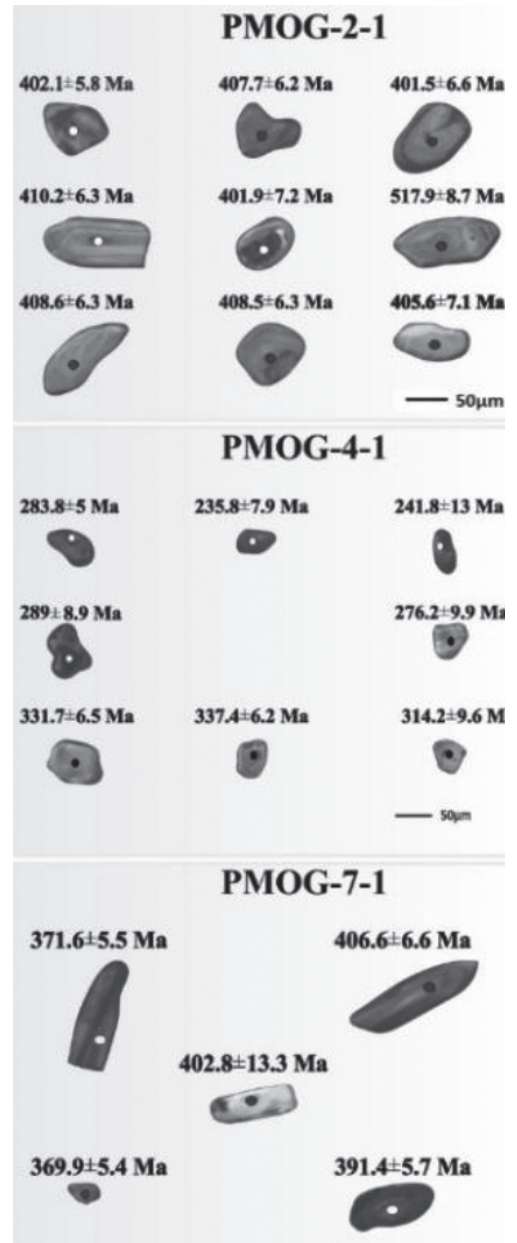

FIGURA 7. Imágenes de catodoluminiscencia (CL) de circones representativos estudiados.
En el contexto de las ideas antes referidas y a la luz de los nuevos datos reportados, es posible establecer que el miembro basal de la Formación Floresta aflorante en el área de Mogotes-San Joaquín, es temporalmente correlacionable con la Formación Tíbet documentada en el Macizo de Floresta (Ulloa et al., 2003; Cardona et al., 2016), es decir, son rocas con una máxima edad estratigráfica del Devónico Temprano (Emsiano). A diferencia de lo reportado para el Macizo de Floresta, en este sector del SW del Macizo de Santander, estas rocas desarrollan una clara reorientación preferente de sus componentes, generando en la roca superficies filiticas. No obstante, esta reorientación preferente o foliación metamórfica en el miembro basal, se considera relacionada más con el desarrollo de protomilonitas (paralelas o subparalelas a los antiguos planos de estratificación $\mathrm{S}_{0}$ ), es decir, son rocas afectadas por metamorfismo dinamo-térmico.

Contrario a las rocas del miembro basal ya citado, las rocas del miembro medio (con su naturaleza sedimentantaria bien preservada, salvo aquellos sectores puntuales con presencia local de pizarrosidad tectónica perpendicular a los planos $\mathrm{So} \approx \mathrm{S}_{1}$ ) no presentan aspecto de filitas. La máxima edad de depositación (o máxima edad estratigráfica) obtenida para estas rocas (aproximadamente límite Devónico Medio y Tardío), permite correlacionar estas litologías con la propia Formación Floresta del Macizo homónimo. En lo referente al miembro superior, a falta de mayores datos, se asume éste como correlacionable con la Formación Cuche (?), tomando en consideración lo ya referido en anteriores líneas.

En éste nuevo marco de ideas, la propuesta de Cardona et al. (2016), en lo referente a que las rocas en este sector de la Cordillera Oriental fueron afectadas por un metamorfismo regional a finales del Carboníferocomienzos del Pérmico, se descartaría por las evidencias ya referidas. Sin embargo, no se excluye que en ese intervalo de tiempo hayan podido tener lugar procesos locales de metamorfismo dinamo-térmico en el MS.

Finalmente, la propuesta de Moreno-Sánchez et al. (2005), en el sentido que las rocas del sector de Mogotes y San Joaquín son todas de edad PermoCarbonífero y que por consiguiente se debería dar a éstas el nombre de Formación Mogotes en reemplazo de Formación Floresta, también debería ser descartada a la luz de los nuevos datos. La razón es que las rocas del tramo Mogotes-Cerro Los Cacaos, registran eventos de depositación durante el Devónico, El Carbonífero Temprano y también durante El Pérmico (Cisuraliense). Estos diferentes intervalos del registro sedimentario son 
diferenciables en el terreno y han sido delimitados entre ellos, tal como se sugiere en la FIGURA 1.

\section{CONCLUSIONES}

Las rocas aflorantes en el área Mogotes-San Joaquín (sector SW del Macizo de Santander), representan un importante registro sedimentario desarrollado durante el Paleozoico Tardío. Las rocas del área de estudio, agrupadas dentro del denominado miembro basal de la Formación Floresta, se correlacionan en edad con la Formación Tíbet, descrita en el Macizo de Floresta (considerado que su máxima edad estratigráfica es Devónico Temprano; $\approx 410 \mathrm{Ma}$ ). Por otro lado, el miembro medio de la Formación Floresta en el área de estudio presenta una máxima de edad de depositación Devónico Tardío (Frasniense), mientras que el miembro superior, en ausencia de edades absolutas, se presume que sea igualmente Devónico Tardío (?). Estas rocas de edad Devónico contrastan composicionalmente con las rocas del Carbonífero Temprano y el Pérmico (C-P) reconocidas igualmente en el área de estudio, dado que estas presentan un predominio de calizas y lodolitas, respectivamente.

La presencia de fósiles de braquiópodos (del genero Productus sp.) y crinoideos del Paleozoico Tardío, tal como se reporta en Moreno-Sánchez et al. (2005), corrobora la existencia de rocas de esta edad C-P en el área de estudio, pero estos datos no pueden ser extrapolados a las litologías infrayacentes (Formación Floresta). Por esta razón, la propuesta de llamar 'Formación Mogotes' a todo el registro sedimentario del tramo objeto de estudio (en reemplazó de la Formación Floresta Metamorfoseada), debe ser descartada; no obstante, los datos paleontológicos allí citados sin duda alguna seguirán siendo muy valiosos, en el momento de estudiar más a fondo el registro sedimentario de edad Carbonífero allí presente. Considerando todos estos aspectos, en éste trabajo se sugiere que las rocas aquí referidas como C-P, podrían ser correlacionadas con la unidad denominada Paleozoico del Río Nevado (Stibane y Forero, 1969; Vargas et al., 1981).

Finalmente, los datos aquí reportados contradicen lo indicado en Cardona et al. (2016), en lo referente a la presencia en el MS de rocas con metamorfismo regional de finales del Carbonífero-comienzos del Pérmico. La presencia de rocas de edad Devónica sin metamorfismo regional en este sector del MS, entre otros aspectos, evidentemente no apuntan en ese sentido. Sin embargo, no se descarta que para el periodo de tiempo señalado haya podido desarrollarse localmente procesos de metamorfismo dinamo-térmico (o de otro tipo).

\section{AGRADECIMIENTOS}

Los autores expresan un profundo agradecimiento a la Universidad Industrial de Santander (UIS) y a la Vicerrectoría de Investigación y Extensión-VIE, por el apoyo financiero brindado a este trabajo mediante el proyecto 1882, titulado: Caracterización litológica y condiciones del metamorfismo de la unidad 'Filitas de San Pedro' (Macizo de Santander, Colombia). A la Escuela de Geología por apoyar siempre las actividades encaminadas a generar nuevo conocimiento geológico de nuestro territorio nacional. A las autoridades civiles, militares, eclesiásticas y habitantes en general del área rural y urbana de los Municipios Mogotes y San Joaquín, por toda la hospitalidad y colaboración brindadas durante las visitas que los autores y sus estudiantes hemos realizado al área de estudio. Asimismo, manifestamos nuestra inmensa gratitud a todos aquellos estudiantes de la Escuela de Geología de la UIS, quienes realizaron sus prácticas de Campo II en esa hermosa tierra, por su entusiasmo y sed de conocimiento. Sin ese insumo de parte de ellos, este documento seguramente no hubiese salido a la luz. Igualmente expresamos nuestro sentimiento de gratitud a Hernando Mendoza por su valioso acompañamiento durante varios días de campo, por su amistad y por todo el tiempo compartido con el primer autor en el marco de muchas e interesantes tertulias geológicas. A Giovanny Jiménez y Francisco Velandia, por sus valiosos comentarios, amistad y por esa contagiosa pasión por la geología y el ejercicio docente. A Vanessa Rey por su colaboración en la elaboración de algunas figuras. Finalmente, los autores expresan un profundo agradecimiento a los dos evaluadores anónimos del presente trabajo, por sus valiosos comentarios y sugerencias.

\section{REFERENCIAS}

Boinet, T., Bourgois, J., Bellon, H., and Toussaint, J. (1985). Age et repartition du magmatism Premesozoique des Andes de Colombie. Comptes rendus hebdomadaires des séaces de L'Académie des Sciences. Serie D: Sciences Naturalles, 300(II), 445-450.

Botero, G. (1950). Reconocimiento geológico del área comprendida por los municipios de Belén, Cerinza, Corrales, Floresta, Nobsa y Santa Rosa de Viterbo Depto de Boyacá. Compilación de estudios geológicos Oficina Colombia, 8: 245-311.

Cardona, A., Valencia, V., Lotero, A, Villafañez, Y., and Bayona, G. (2016). Provenance of middle to late Palaeozoic sediments in the 
northeastern Colombian Andes: implications for Pangea reconstruction. Internatonal Geology Review, 58(15), 1914-1939. doi: 10.1080/00206814.2016.1190948.

Caster, K. (1939). A Devonian fauna from Colombia. Bulletins American Paleontology, 24(83), 1-14.

Chang, Z., Vervoort, J.D.,McClelland, W.C., and Knaack, C. (2006). U-Pb dating of zircon by LAICP-MS. Geochemistry, Geophysics, Geosystems, 7(5), 1-14. doi: 10.1029/2005GC001100.

Cordani, U., Cardona, A., Jimenez, D., Liu, D., and Nutman, A. (2005). Geochronology of Proterozoic basement inliers in Colombian Andes: tectonic history of remnants of a fragmented grenville belt. In: A. Vaughan, P. Leat, R. Pankhurst (Ed.), Terrane processes at margins of Gondwana (pp. 329-346). Geological Society, London, Special Publications.

Correa, M.A.M., Rodríguez, G.G., Arango, M.M.I., Zapata, G.G., y Bermúdez, C.J.G. (2016). Catálogo de unidades litoestratigráficas de Colombia. Batolito de Mogotes. Cordillera Oriental. Departamento de Santander. Medellín.

Clavijo, T.J., Mantilla, F.L.C., Pinto, V.J., Bernal, L., y Pérez, A. (2008). Evolución geológica de la Serranía de San Lucas, Norte del Valle Medio del Magdalena y Noroeste de la Cordillera Oriental. Boletín de Geología, 30(1), 45-62.

García-Ramírez, C., Rey-León, V., y Valencia, V. (2017). Ortoneises en la Franja Silos-Babega, Macizo de Santander, Colombia: evidencias de la orogenia famatiniana en los Andes del norte. Andean Geology, 44(3), 307-327. doi: 10.5027/ andgeov44n3-a04.

Mantilla-Figueroa, L.C., Bissig, T., Valencia, V., and Hart, C. (2013). The magmatic history of the Vetas-California mining district; Santander Massif, Eastern Cordillera, Colombia. Journal of South American Earth Sciences, 45, 235-249. doi: 10.1016/j.jsames.2013.03.006.

Mantilla-Figueroa, L., García-Ramírez, C., Ríos-Reyes, C., Castellanos, O., Valencia, V., y Camacho, D. (2015). Geocronología U-Pb en zircones detríticos de rocas metasedimentarias del Macizo de Santander (Cordillera Oriental, Colombia): Implicaciones estratigráficas. Memorias $\mathrm{XV}$ Congreso Colombiano de Geología. Bucaramanga.
Mantilla-Figueroa, L.C., García-Ramírez, C.A., y Valencia, V.A. (2016a). Propuesta de escisión de la denominada 'Formación Silgará' (Macizo de Santander, Colombia), a partir de edades $\mathrm{U}-\mathrm{Pb}$ en circones detríticos. Boletín de Geología, 38(1), 3350. doi: 10.18273/revbol.v38n1-2016002.

Mantilla-Figueroa, L.C., García-Ramírez, C.A., Valencia, V.A. (2016b). Nuevas evidencias que soportan la escisión de la Formación Silgará y propuesta de un nuevo marco estratigráfico para el basamento metamórfico del Macizo de Santander (Cordillera Oriental de Colombia). Revista de la Academia Colombiana de Ciencias Exactas, Físicas y Naturales, 40(155), 320-336. doi: 10.18257/raccefyn.303.

Moreno-Sánchez, M., Gómez-Cruz, A.d.J., y CastilloGonzález, H. (2005). La Formación Floresta Metamorfoseada (sensu Ward et al., 1973) no es la Formación Floresta sin metamorfosear. Memorias $X$ Congreso Colombiano de Geología. Bogotá.

Restrepo-Pace, P.A., and Cediel, F. (2010). Northern South America basement tectonics and implications for paleocontinental reconstructions of the Americas. Journal of South American Earth Sciences, 29(4), 764-771. doi: 10.1016/j. jsames.2010.06.002.

Royero, G.J.M., y Clavijo, T.J. (2001). Mapa geológico generalizado del departamento de Santander. Escala 1:400.000. INGEOMINAS. Memoria explicativa. Bogotá.

Stibane, F., y Forero, A. (1969). Los afloramientos del Paleozoico en la Jagua (Huila) y Río Nevado (Santander del Sur). Geología Colombiana, 6, 31-66.

Ulloa, C., Rodríguez, E., y Rodríguez, G. (2003). Geología de la Plancha 172-Paz del Río. INGEOMINAS. Memoria explicativa, 109 p. Santa Fe de Bogotá.

Van Der Lelij, R., Spikings, R., Ulianov, A., Chiaradia, M., and Mora, A. (2015). Palaeozoic to Early Jurassic history of the northwestern corner of Gondwana, and implications for the evolution of the Iapetus, Rheic and Pacific Oceans. Gondwana Research, 31, 271-294. doi: 10.1016/j.gr.2015.01.011.

Vargas, H.R., Arias, T.A., Jaramillo, C.L., y Téllez, I.N. (1981). Geología de las planchas 136-Málaga y 152-Soatá, cuadrángulo I-13. Instituto Nacional 
de Investigaciones Geológico-Mineras. Memoria Explicativa, pp. 1-76.

Velandia, F., García, H., López, J., Bermúdez, M., Zuluaga, C., y Taboada, A. (2017). Modelo estructural del Macizo de Santander y zonas adyacentes. XVI Congreso Colombiano de Geología y III Simposio de Exploradores. Santa Marta, Colombia.

Ward, D., Goldsmith, R., Cruz, B., Jaramillo, C., y Restrepo, H. (1973). Geología de los Cuadrángulos H-12, Bucaramanga y H-13, Pamplona, departamento de Santander. U.S. Geological Survey e INGEOMINAS. Boletín Geológico, XXI(1-3): 1-132.

Zuluaga, C., Amaya, S., Urueña, C., and Bernet, M. (2017). Migmatization and low-pressure overprinting metamorphism as record of two preCretaceous tectonic episodes in the Santander Massif of the Andean basement in northern Colombia (NW South America). Lithos, 274-275, 123-146. doi: 10.1016/j.lithos.2016.12.036.

Luis Carlos Mantilla-Figueroa

ORCID: 0000-0002-2112-8041

Carlos Alberto García-Ramírez

ORCID: 0000-0002-4727-0708

Trabajo recibido: octubre 10 de 2017

Trabajo aceptado: noviembre 30 de 2017 